\title{
STRATEGIC BEHAVIOR IN ASCENDING-PRICE MULTIPLE-OBJECT AUCTIONS
}

\author{
Flávio Marques Menezes*
}

\section{Resumo}

Examinamos, neste trabalho, uma situação na qual um número divisivel de objeto é vendido através de um leilão de preços ascendentes onde alguns jogadores se comportam de forma não-estratégica. Esse tipo de leilão tem sido utilizado no Programa Brasileiro de Privatização.

Em adição, testamos algumas conjecturas com relação ao comportamento dos participantes através de um algoritmo genético. Nesse caso, agentes com inteligência artificial substituem os participantes no jogo. Os resultados desse algoritmo sugerem que quando jogadorcs inicialmente não-estratégicos têm a oportunidade de participar do leilão repetidamente, eles aprendem a se comportar de forma ótima em poucas rodadas.

Finalmente, concluímos que na meciida em que o número dos jogadores que se comportam estrategicamente diminui, a solução se aproxima do equilíbrio competitivo. Assim, qualquer previsão relacionada ao resultado esperado em tais leilões depende da estrutura do mercado.

\section{Abstract}

In this paper we examine an ascending-price multiple-object auction that has been used in the brazilian privatization process. We assume that artificially intelligent agents replace bidders in the game. We incorporate the existence of small players who cannot play strategically. Our results suggest that strategic bidders learn how to play in few rounds. We also conclude that as the number of players behaving strategically decreases the solution approaches the competitive one. Thus, any predictions related to the results of the auctions must be conditional on the market structure.

\section{Introduction.}

The issue of how prices are formed in real-world markets has been implicit in the development of economic theory. For instance,

*Australian National University, Canberra, Australia

I thank Richard Engelbrecht-Wiggans, Charles Kahn and two anonymous referees for many useful suggestions. All remaining errors are of my own. I acknowledge the financial support of CNPq (Brazil).

R. de Econometria Rio de Janeiro v.14, $\mathrm{n}^{2} 1, \mathrm{p} .1-42$ abril 1994/outubro 1994


in the theory of competitive equilibrium prices are determined by a fictitious player (the Walrasian auctioneer). On the other hand, oligopoly models yield equilibrium price vectors and not equilibrium processes for the determination of prices. Further, auction theory, which appears as a natural model to understand this process, usually explains price formation for single objects based on the auction institutions and on individuals' values for the object being auctioned. Finally, bargaining theory explores the negotiation process that players must undergo before finalizing any sale. This paper is inserted in the context of understanding the links between these theories. ${ }^{1}$

In Menezes (1993-a,b), we examine the outcome of ascendingprice multiple-object auctions where two bidders with convex, continuous downward sloping demand functions are disputing a fraction of a total of $T S$ divisible objects. The auctioneer starts the game by announcing an initial price and by asking both players to submit bids simultaneously (the fraction of the total amount of objects wanted at that price). As long as the total amount of bids $(T B)$ is greater than $T S$ the auctioneer keeps announcing a higher price and asking for new bids until $T B \leq T S$, when each bidder receives the amount of objects they asked for. Bidders are allowed to bid any real number in the interval $[0, T S]$, and the auctioneer announces the total amount bid after each round. Bidders are not allowed to increase their bids from one round to the next, i.e., the sequence of bids must be non-increasing.

Menezes (1993-a) indicates that when players are fully informed about each others' types, a sale is completed at the initial price in any pareto perfect equilibrium. In these equilibria players receive allocations that are less than or equal to their demands at that price and that yield at least as much profits as the minimum they could

\footnotetext{
${ }^{1}$ Milgrom (1987), for example, stresses the importance of studying this relationship. Wilson (1987-a) provides an introduction to this line of research. Hansen (1988), who examined auctions with endogenous quantity as an alternative to price-setting oligopoly models, is an example of the importance of such approach. Wilson (1987-b), for example, suggests that the theory of bid-ask markets may be useful to establish a game-theoretic foundation for the Walrasian model of perfect competition in the case of pure exchange with incomplete information. He also explores the links between auctions and bargaining theory.
} 
obtain by waiting until the price reaches the level immediately below the market clearing price. This suggests that such mechanism may have disappointing effects in terms of revenue maximization. That is, players capture virtually all trading surplus.

Of course, the above results require both players to bid strategically. However, evidence seems to suggest that in real auctions there are both strategic players and small bidders who cannot participate in a strategic manner. For instance, in the Treasury auction primary dealers (approximately 40 ) received $76 \%$ of bill awards and $87 \%$ of notes and bonds awards in the first 9 months of $1991 .^{2}$ Moreover, the Fed accepts non-competitive bids (up to US\$ 1 million) with the award being based on the average price of the competitive bids.

In this paper we investigate the effects on equilibrium selection of having these small bidders behaving in a competitive manner, i.e., as in a competitive equilibrium, each player bids according to his "true" demand at any particular price. Our analysis suggests that strategic bidders may choose to accommodate their opponents' competitive bids so as to achieve an agreement sooner, even if it means to accept smaller awards.

Moreover, observe that when there is only one strategic bidder playing against possibly many competitive bidders, his choices are simple: he either waits until the price reaches the competitive level or for any price lower than that he bids an amount equivalent to the excess supply, whichever maximizes his total profits. However, when there are two or more strategic players, their strategy space becomes far more complex. Suppose there are two strategic bidders and many competitive players. These two players are now disputing a total number of objects (i.e., the excess supply) that increases as the price increases. Now it may be the case that rational players decide to wait until the competitive price is reached. Thus, in order to test these predictions, we introduce adaptive artificially intelligent $(A A I)$ agents to replace bidders in the game.

This paper is organized as follows. In section 2, we indicate the equilibria when all players behave competitively, all players behave strategically and when there is a mix of these two behaviors. Fur-

${ }^{2}$ See the Joint Report on the Government Securities Market (1992). 
ther, we present a conjecture about the format of equilibrium when there are two or more strategic bidders playing against competitive bidders. We introduce, in section 3 , a specific example where players are replaced by $A A I$ agents. By using this example, we show that our conjectures are correct when players are able to learn how to play the game. Finally, the main conclusions are summarized in section 4 .

\section{The equilibrium analysis.}

In this section we examine the effects on equilibrium selection of having some players not being able to bid strategically. A competitive player always bids an amount equivalent to his true demand. Thus, whenever all players behave competitively, the auction continues until the price reaches a level where total demand is equal to $T S$, and bidders will receive the amounts they asked for at that price. Of course, this solution concept is equivalent to the Walrasian equilibrium.

The interesting cases are those where there is a mix of players behaving strategically and competitively. We first characterize the equilibrium where there is only one strategic player. We assume that Bidder $a$ represents a strategic player while Bidder $b$ represents a competitive one. (We can interpret Bidder b's bids as representing the linear sum of many small players' bids). Our equilibrium notion for this game is equivalent to a solution where Player $b$ always bids according to his "true" demand and Player $a$ takes his opponent's actions as given and maximizes profits.

We solve first the full information case. (See figure 1). For any price $p_{t}$, Player $b$ always bids $D_{b}\left(p_{t}\right)$. Player $a$, on the other hand, has to decide whether to accommodate his opponent's demand by bidding an amount less than or equal to $T S-D_{b}\left(p_{t}\right)$ at price $p_{t}$. In any case, Player $a$ is guaranteed to be awarded $D_{a}\left(p^{*}\right)$, if the price reaches that level. Note that $p^{*}$ still represents the price such that total demand is equal to $T S$. We assume that $p_{0}<p^{*}$ :

Player $a$ 's profits at any particular round $t$ are given by:

$$
\pi_{a}\left(D_{a}\left(p_{t}\right), X_{t}\right)= \begin{cases}\int_{0}^{X_{t}} D_{a}^{-1}(x) d x-p_{t} X_{t}, & \text { if } X_{t} \leq \max \left\{0, T S-D_{b}\left(p_{t}\right)\right\} \\ 0, & \text { otherwise }\end{cases}
$$


Where $\pi_{a}(\cdot, \cdot)$ denotes Player $a$ 's expected profits from bidding $X_{t}$ given that his demand is equal to $D_{a}\left(p_{t}\right)$. Consequently, Player $a$ chooses his strategy profile over time by solving the following maximization problem:

$$
\begin{array}{ll}
\text { (P1) } \quad \max _{\left\{X_{t}, t\right\}} \pi_{a}\left(D_{a}\left(p_{t}\right), X_{t}\right) \\
\text { s.t. } \quad \text { (i) } p_{t} \leq p^{*} \\
\\
\text { (ii) } \quad X_{t} \leq X_{t-1}, X_{t} \leq \max \left(0, T S-D_{b}\left(p_{t}\right)\right), t \leq 1
\end{array}
$$

We denote by $W_{T}$ the solution of $(P 1)$, and let $T$ represent the time period when this maximum value is achieved. ${ }^{3}$ Therefore, this auction game ends at round $T$, with the agreement $\left(W_{T}, D_{b}\left(P_{T}\right)\right)$ at price $p_{T}$ and $W_{T}=T S-D_{b}\left(p_{T}\right)$. Note that both pairs $\left(T S-D_{b}\left(p_{0}\right), D_{b}\left(p_{0}\right)\right)$ at price $p_{0}$ and $\left(D_{a}\left(p^{*}\right), D_{b}\left(p^{*}\right)\right)$ at price $p^{*}$ are possible agreements for this auction game.

For all rounds $0 \leq t<T$, Player $a$ may bid any amount satisfying two restrictions: (a) bids are consistent with having the game to persist until time $T$, and (b) bids are non-increasing. For instance, the sequences of Player a's bids of length $T\left(W_{T}, \ldots, W_{T}\right)$ and $\left(T S, \ldots, T S, W_{T}\right)$ represent possible equilibrium profiles. Note that as in Menezes (1993-a), restriction (b) apparently does not play any important role in equilibrium selection. It only eliminates some pre-agreement moves. The previous analysis may be summarized as follows.

Proposition 1. The outcome of this auction game, for $p_{0} \leq p^{*}$, is given by the agreement $\left(W_{T}, D_{b}\left(p_{T}\right)\right)$, where $W_{T}$ is the solution for $(P 1)$. At any period $t<T$, Player $b$ always bids an

\footnotetext{
${ }^{3}$ For this maximal value to be always achievable we are considering that $p$ varies continuously. Evidently, the practical implementation of such mechanism is dubious, and we interpret this solution as the limit of a constrained maximization problem (where prices increase discretely) as $\delta$, the price increment, approaches 0 . For instance, in the example that follows we take $\delta$ and the initial price such that the equilibrium obtained is equal to the unconstrained solution. Notice that a solution always exists in this case.
} 
amount cquivalent to his demand at price $p_{t}$ whilc Playrer a's sequence of bids in equilibrium may be represented by profiles of the typc $\left(W_{0}, W_{1}, \ldots, W_{T-1}, W_{T}\right)$, with $W_{0} \geq W_{1} \geq \ldots \geq W_{T-1} \geq W_{T}$.

Further, notice that for $p_{0}>p^{*}$, the only equilibrium is the agreement $\left(D_{a}\left(p_{0}\right), D_{b}\left(p_{0}\right)\right)$ at price $p_{0}$, since this strategy clearly maximizes Player $a$ 's profits, given that Player b's actions are fixed. Next we provide an example where we are able to compute the different outcomes for the various combinations of players' behavior.

EXAMPLE: The demand functions of players $a$ and $b$ are identical and are given by $D_{a}\left(p_{t}\right)=D_{b}\left(p_{t}\right)=5-p_{t}$. The total number of objects is equal to 4 , and bidders are allowed to bid any real number in the interval $[0,4]$. We assume that $p_{0}=2$ and that the price increment is equal to $\cdot 1$.

a) Both players behave competitively: This is the easiest case to solve, since it suffices to compute the competitive equilibrium allocation. Solving $10-2 p_{t}=4$ yields $p^{*}=3$, and consequently $D_{a}(3)=D_{b}(3)=2$. The total amount of profits is given by $\pi_{a}=\pi_{\iota}=2$.

b) Both players behave strategically: The solution for this particular situation was given in Menezes (1993-a). Both payers bid an amount so that they receive, at the initial price $p_{0}$, an allocation that yields at least as much profits as the minimum they could receive at price $2.9(2.185)$ so that there are a plethora of equilibria.

In this case, they both receive allocations in the interval $[.85,3]$ so that their sum is equal to 5 . These pairs of allocations yield profits strictly higher than the competitive allocations. Those pairs include the symmetric equilibrium where each bidder receives the amount that they would get at the market clearing price (2 unities), with profits $\pi_{a}=\pi_{b}=4$.

c) Player $a$ behaves strategically, while Player $b$ bids competitively: Player $b$ always bids an amount equivalent to his demand, while Player $a$ solves $(P 1)$, achieving the outcome $(1.3,2.7)$ at price 2.3. The amount of profits is given by $\pi_{a}=2.665$ and $\pi_{b}=3.645$.

d) Player $a$ behaves competitively, while Player $b$ behaves strategically: By symmetry the solution is given by $(2.7,1.3)$ at the 
same price (2.3), and profits are $\pi_{a}=3.645$ and $\pi_{\iota}=2.665$.

We now consider the situation where Player $b$ may either have a high demand $\left(D_{b H}\left(p_{t}\right)\right)$ or a low demand $\left(D_{b L}\left(p_{t}\right)\right)$. (See figure 2). Player $b$ observes his opponent's demand, while Player $a$ only knows that there is a probability $k_{0}$ that his opponent is a high demander and a probability $1-k_{0}$ that he is a low demander. Both players know their own types. We denote by $p_{L}$ and $p_{H}$ the prices such that total demand is equal to total supply considering that Player $b$ has, respectively, a low demand or a high demand. We also assume for the moment that $p_{0}<p_{L}<p_{H}$.

To find the possible equilibria of this mechanism we must realize first that although Player $a$ does not know b's demand at round 0 , this uncertainty is resolved at round 1 . Conditional on not reaching an agreement at period 0, Player $a$ solves:

$$
\begin{aligned}
& \text { (P2) } \quad \max _{\left\{X_{t}, t\right\}} \pi_{a}\left(D_{a}\left(p_{t}\right), X_{t}\right) \\
& \text { s.t. } \quad \text { (i) } p_{1} \leq p_{t} \leq p^{*} \\
& \\
& \text { (ii) } X_{t} \leq X_{t^{\prime}-1} X_{t} \leq \max \left(0, T S-D_{b}\left(p_{t}\right)\right), t \geq 1
\end{aligned}
$$

Where $\pi_{a}(\cdot, \cdot)$ is defined as in $(1)$, with $D_{b}\left(p_{t}\right)$ being the realized value of Player $b$ 's demand and $p^{*}$ corresponding to either $p_{L}$ or $p_{H}$. We denote the solution to $(P 2)$ by $\widehat{W}_{T}$, where $\mathrm{T}$ represents again the period when the agreement $\widehat{W}_{T}$, is achieved. The question is then how Player $a$ bids at period 0 .

We argue that Player $a$ solves, at period 0 , problem $(P 2)$ for $D_{b H}\left(p_{t}\right)$, for $t \geq 1$, without considering restriction (ii) for $t=1$. We denote the solution of those problems (i.e., for a high and a low demander) by, respectively, $\widehat{S}$ and $\widehat{Y}$. Player $a$ then compare the payoffs from any round 0 strategy with $k_{0} \pi_{a}\left(\widehat{S}+\left(1-k_{0}\right) \pi_{a}(\widehat{Y})\right.$, where $\pi_{a}(\widehat{S})$ and $\pi_{a}(\widehat{Y})$ represent the total amount of profits from selecting those optimal solutions to the different versions of problem $(P 2)$, given Player a's demands at that levels. In order to characterize the set of possible equilibrium bids for Player $a$ at period 0 we consider three distinct cases: 
CASE 1: $0<T S-D_{b H}\left(p_{0}\right)<T S-D_{b L}\left(p_{0}\right)$. Here we have the following potential equilibrium bids:

(a) By bidding $X_{0}=T S-D_{b H}\left(p_{0}\right)$, Player a guarantees that the auction ends with probability one, and he will receive the amount bid. Clearly, this is an equilibrium as long as:

$$
\pi_{a}\left(D_{a}\left(p_{0}\right), T S-D_{b H}\left(p_{0}\right) \geq\left(1-k_{0}\right) \pi_{a}\left({ }_{a}\left(p_{0}\right), T S-D_{b L}\left(p_{0}\right)\right)\right.
$$

and

$$
\pi_{a}\left(D_{a}\left(p_{0}\right), T S-D_{b H}\left(p_{0}\right)\right) \geq k_{0} \pi_{a}(\widehat{S})+\left(1-k_{0}\right) \pi_{a}(\widehat{Y})
$$

Condition (2) requires that this strategy yields a payoff greater or equal than the payoff generated by bidding as if $b$ were a low demander (which induces an agreement with probability $1-k_{0}$ ), while condition (3) establishes that this strategy must also be optimal with respect to the expected value of having the game to continue. Hence, if (3) is not satisfied, Player $a$ bids an amount greater or equal than $\max \{\widehat{S}, \widehat{Y}\}$ so as to satisfy the monotonicity property of the sequence of bids.

(b) By bidding $X_{0}=T S-D_{b L}\left(p_{0}\right)$, Player $a$ expects to reach an agreement at period 0 with probability $1-k_{0}$. Consequently, this strategy is an equilibrium for the auction-like game if the following conditions are satisfied:

$$
\left(1-k_{0}\right) \pi_{a}\left(D_{a}\left(p_{0}\right), T S-D_{b L}\left(p_{0}\right)\right) \geq \pi_{a}\left(D_{a}\left(p_{0}\right), T S-D_{b H}\left(p_{0}\right)\right)
$$

and

$$
\left(1-k_{0}\right) \pi_{a}\left(D_{a}\left(p_{0}\right), T S-D_{b L}\left(p_{0}\right)\right) \geq k_{0} \pi_{a}(\widehat{S})+\left(1-k_{0}\right) \pi(\widehat{Y}) .
$$

The interpretation of conditions (4) and (5) is analogous to that of letter (a). Note, further, that if this strategy induces an equality sign in condition (4), then we have to look at those mixed strategies satisfying an equivalent version of conditions (3) and (5). We also assume that Player $a$ is risk-neutral. 
(c) Consider a bid of $X_{0}$, with $T S-D_{b H}\left(p_{0}\right)<X_{0}<T S-D_{b L}\left(p_{0}\right)$. This is not an equilibrium bid, since if $b$ is high, then $a$ doesn't receive $X_{0}$ anyway, and if $b$ is low, then $a$ is not maximizing profits.

(d) $X_{\mathrm{O}}<T S-D_{b H}\left(p_{0}\right)$ is not an equilibrium bid either, since Player $a$ doesn't maximize profits for any of his opponent's type.

(e) In the event that the strategies outlined in (a) and (b) are not equilibria for this game, then Player $a$ 's dominant strategy is to bid an amount $X_{0}>T S-D_{b L}\left(p_{0}\right)$, which induces the game to continue to the next round with probability one. However, he must bid at least $\max \{\widehat{S}, \widehat{Y}\}$ so as to satisfy the monotonicity property of the sequence of bids. Consequently, if conditions (2) and (3) or (4) and (5) are not satisfied, then $X_{\mathrm{O}} \in[\max \{\widehat{S}, \widehat{Y}\}, T S]$.

CASE 2: $T S-D_{b H}\left(p_{0}\right)<0<T S-D_{b L}\left(p_{0}\right)$. For this case we have potentially three equilibrium bidding strategies:

(f) By bidding $X_{0}=T S-D_{b L}\left(p_{0}\right)$, there will be an agreement with probability $1-k_{0}$. For this strategy to be an equilibrium conditions (4) and (5) must be satisfied.

(g) Bidding $X_{0}<T S-D_{b L}\left(p_{0}\right)$ is not an equilibrium, since if $b$ is high, then, the game continues anyway, and if $b$ is low, Player $a$ does not maximize profits. (Remember that $p_{0}<p_{L}$ implies that $\left.D_{a}\left(p_{0}\right) \geq T S-D_{b L}\left(p_{0}\right) \cdot\right)$

(h) If the strategy described in (f) is not an equilibrium, then $X_{\mathrm{O}}>T S-D_{b L}\left(p_{0}\right)$. Specifically, $X_{0} \in[\max \{\widehat{S}, \widehat{Y}\}, T S]$. The explanation is the same as in letter (e).

CASE 3: When $0<T S-D_{b H}\left(p_{0}\right)<T S-D_{b L}\left(p_{0}\right)$, for any bid submitted by Player $a$ the game continues with probability one, since his bids are limited to the interval $[0, T S]$. Hence:

(i) For the reasons outlined in letter (e), $X_{0} \in[\max \{\widehat{S}, \widehat{Y}\}, T S]$.

Notice that by considering the cases where $T S-D_{b H}\left(p_{0}\right)=0$ we rule out the equilibrium described in (a). If $T S-D_{b L}\left(p_{0}\right)=0$ then the aralysis is as described in letter (i). (Given the assumptions of the auction, the solution of $(P 2)$ is greater than zero). The next two propositions summarize the solution process for this auction game. 
Proposition 2. The set of possible bids for Playcr a at period 0 is described by $\left\{T S-D b H\left(p_{0}\right), T S-D_{b L}\left(p_{0}\right),[\max \{\widehat{S}, \widehat{Y}\}, T S]\right\}$.

Proposition 3. The solution for the game is detcrmined by the following algorithm:

Step 1: If conditions (2) and (3) are satisfied, then the agreement $\left(T S-D_{b H}\left(p_{0}\right), D_{\iota}\left(p_{0}\right)\right)$ is reached at period 0 regardless of $b$ 's type.

STEP 2: If instead conditions (4) and (5) are satisfied, then the agreement $\left(T S-D_{b L}\left(p_{0}\right), D_{b L}\left(p_{0}\right)\right)$ is reached at price $p_{0}$ when $b$ is low. If $b$ is high then the game continues to the next period. In words, Player $a$ made a bet and lost. Hence, the outcome is given by the solution of (P2) with (ii) replaced by $X_{t} \leq T S-D_{b L}\left(p_{0}\right)$, for $t \geq 1$. Eventually, the solution of this problem may be also given by the same value of $\widehat{S}$ (in the event that this amount is less than $\left.T S-D_{b L}\left(p_{0}\right)\right) .{ }^{4}$

STEP 3: If conditions (2) and (3) or (4) and (5) are not satisfied, then the outcome of the game is given by $\left(\widehat{S}, D_{b H}\left(p_{T^{\prime}}\right)\right)$ if $b$ is high and $\left(\widehat{Y}, D_{b L}\left(p_{T^{\prime \prime}}\right)\right)$ if $b$ is low, where $T^{\prime \prime}$ denotes the round where $\widehat{Y}$ is reached. The sequence of bids must be such that $X_{0} \leq \max \{\widehat{S}, \widehat{Y}\}$ and $X_{1} \leq \cdots \leq X_{T^{\prime}-1} \leq \widehat{S}$, if $b$ is high and $X_{1} \leq \cdots \leq X_{T^{\prime \prime}-1} \leq \widehat{Y}$, if $b$ is low.

Furthermore, let's examine how the solution above would change if we consider $p_{L}<p_{0}<p_{H}$. Conditions (2) and (4) should be replaced, respectively, by:

$$
\begin{aligned}
& \pi_{a}\left(D_{a}\left(p_{0}\right), T S-D_{b H}\left(p_{0}\right)\right) \geq\left(1-k_{0}\right) \pi_{a}\left(D_{a}\left(p_{0}\right), D_{a}\left(p_{0}\right)\right) \\
& \left(1-k_{0}\right) \pi_{a}\left(D_{a}\left(p_{0}\right), D_{a}\left(p_{0}\right)\right) \geq \pi_{a}\left(D_{a}\left(p_{0}\right), T S-D_{b H}\left(p_{0}\right)\right)
\end{aligned}
$$

Case (3) is ruled out, because demand functions are non-negative. Finally, it is straightforward to see that if $p_{L}<p_{H}<p_{0}$, then the unique solution of this auction game is given by the agreement $\left(D_{a}\left(p_{0}\right), D_{b}\left(p_{0}\right)\right)$ at price $p_{0}$.

\footnotetext{
${ }^{4}$ Note that the restriction on the sequence of bids is binding herc. If such restriction were withheld then the unique equilibrium would be given by $\left(\widehat{S}, D_{b H}\left(p_{T^{\prime}}\right)\right)$, where $T^{\prime}$ denotes the time period when $\widehat{S}$ is reached.
} 
We just characterize the solution for the auction-like game when one of the players bids competitively while his opponent behaves strategically. With full information, Player a solves a constrained maximization problem to determine if it is worth to accommodate $b^{\prime}$ 's demand at any round before the price reaches $p^{*}$, when $T S=\mathcal{T} B$. In the presence of incomplete information, a risk-neutral Player a solves a two-step problem. He first computes the maximization problem $(P 2)$ for the two possible types of Player $b$ 's demand. He then chooses his round-0 strategy by comparing its payoff with the expected value of having the game to continue to the next round (he can achieve that by bidding any amount bigger than $\max \{\widehat{S}, \hat{Y}\})$, and by comparing it with other possible period-0 strategies.

For the rest of this section we examine the cases where there are two or more strategic bidders. First, assume that all players behave strategically (and this is common knowledge). Menezes (1993b) conjectures that under full information our result for two players may be generalized for finite many players and for an appropriate equilibrium notion, that is, in any Coalition-proof equilibrium an agreement is reached at the initial price and each bidder receives an award that is less than or equal to his demand at this price and that guarantees at least as much profits as each player would receive at the price immediately below the market clearing level.

The requirement that each bidder may make a mistake and bid 0 with a certain small probability is crucial to show the existence of such equilibrium. The trade-off between reaching an agreement sooner and reaching an agreement at the competitive price is also important for the existence of this equilibrium. In the next section we test the ability of $A A I$ bidders to learn how to play these equilibrium strategies.

Finally, we consider intermediate cases, where there are, for example, two strategic players and many competitive players. The two strategic bidders face an upward sloping excess supply curve and by waiting they can receive strictly higher amounts than by accommodating their bids to the size of the competitive players' demands. Hence, we conjecture that the results of the previous section can be 
generalized to this particular case (so that we would be able to construct an appropriate version of proposition 1). In many examples, however, strategic players will prefer to wait given the upward sloping excess supply curve and the monotonicity restriction on bids.

\section{Ascending-price multiple-object auctions with $A A I$ play- ers.}

In this section we investigate the outcome of the mechanism described in the previous section when bidders are represented by $A A I$ players. Agents' bids are based on computer algorithms of adaptation, search and learning.

$A A I$ agents haven been used by economists to either search for plausible equilibria in games or to study behavior in laboratory experiments. Marimon, Mcgrattan and Sargent (1990) and Marimon and Miller (1990) are examples of works that fall into first category. Our research also falls into this category. Miller and Andreoni (1990-a) is an example of a work in the second category. Miller and Andreoni (1990-b) use $A A I$ agents not only to explain the results of laboratory experiments but also to suggest new lines of research for auction theory. They apply this technique to explain bidders' behavior in first and second-price auctions. they examine bidders with independent, affiliated and common values.

Specifically, we address two distinct questions. First, we ask whether initially non-strategic bidders, who are able to learn through innovations and mimicking well performing strategies, are able to change their behavior toward a more strategic play. That is, we ask whether the result outlined above is obtained as a solution to this genetic algorithm.

Second, we examine the situation where only a fraction of the existing number of bidders has the ability to change their strategies. These bidders face an upward sloping supply curve. We ask whether they can learn how to play strategically among themselves and what are the effects of their relative size into the outcome of the game. This section is divided into three parts. The first part explains the genetic algorithm used in this simulation. The second contains a brief description of the theoretical results we should expect. The last part 
presents the empirical results.

\subsection{The Genetic Algorithm (GA) ${ }^{5}$.}

We use a GA as an adaptive model of the evolution of a population of strategies. Each player's strategy is described by a string of characters. (In our model these are parameters of a bidding strategy). The population consists of such strategies. Each strategy interacts with other strategies in the population and it is assigned a payoff. Poorly performing strategies are withdrawn from the population, while well performing strategies survive unchanged. This allows learning by mimicking successful strategies. New strategies are created by transforming the poorly performing ones through a genetic operator (mutation), which alters some characters of the string. $\mathrm{Mu}$ tation allows innovation into the learning process. ${ }^{6}$

Next we describe the algorithm employed in the remaining of this section. Initially, five divisible objects are being auctioned. Five bidders with identical demand functions given by $D\left(p_{t}\right)=3-p_{t}$ are disputing these divisible objects. Players are denoted by $a, b, c, d$ and $e$. Players are allowed to submit any non-negative bids. The only restriction is that the sequence of bids must be non- increasing. (This is relaxed later).

The auctioneer starts the bidding at $p_{0}=1$ and continues increasing prices by .1 as long as the total amount bid is greater than 5. The game ends at the first time the total amount bid is less or

\footnotetext{
${ }^{5} \mathrm{GAs}$ were devcloped by Holland (1975). They belong to a larger class of adaptive algorithms such as replicator dynamics and ncural networks. Sce, for cxample, Goldberg (1989). The rationality of the usc of GAs in cconomic models is discussed by Holland and Miller (1991).

"Another genctic operator is known as "crossover". It is exccuted in three steps; (1) a pair of strings is chosen (2) the strings arc placed side by side and a point is randomly chosen somewherc along the length of the strings, and (3) the segments to the left of the point are exchanges between the strings. For cxample, if the alphabet used is binary the crossover of string 1000 and 0111 after the second position produces the offspring strings 1111 and 0000. Crossovers allow us to bias the system toward certain patterns. In this paper we only usc onc genetic operator, namely, mutations. We adapt the concept of mutation, by using a random device to capturc the cvolutionary process in which successful strategies have a higher chance to procecd to the next gencration unchanged.
} 
equal than 5 . If an agreement is not reached until $p_{t}=3$ (i.e., at the $21^{\text {st }}$ stage) then the auction is cancelled and bidders are not awarded any objects.

Bidders are characterized by an array of 21 positive numbers corresponding to a bid for each possible price, i.e., from $p_{0}=1$ until $p_{20}=3$. Their initial strategies are given by their competitive bids at each price, i.e., they bid 2,0 at $p_{0}=1,1.9$ at $p_{1}=1.1$, and so on.

We add players' bids and at the first time they are feasible the allocations are made and we compute the total amount of profits each bidder makes. We consider initially the complete symmetric case. To each player we associate a random number between 0 and 1 . If this random number is smaller than three times the total amount of profits in the previous round then he transfers his entire unchanged array of parameters to the new population. (This implies that immediately after the initial stage each bidder mutates with probability .4).

Otherwise, for each of the 21 parameters of his bidding strategy we associate a random number between 0 and 1 . For the first eleven parameters, if the associated random number is less than or equal to .5 , then we subtract .01 from the respective parameter. If this number is greater than .5 then we add .01 to the parameter. (Remember that we restrict the sequence of bids to be non-increasing so that in this last case his bid cannot be greater than his bid at the previous price). Thus, we assume an initial value of either .01 or -.01 for the mutation. For the last 10 parameters of their bidding strategies, we consider the case where if the associated random number is less than or equal to .5 then that parameter remains unchanged; otherwise it is reduced by .01 This game is repeated a finite number of times (up to 200,000 rounds).

\subsection{Theoretical predictions.}

From the previous section we know that if all players behave competitively, then the equilibrium is reached at $p_{10}=2$ and each bidder receives 1.0, yielding individual profits of .5 . On the other hand, if they all play strategically, we argue that there is a sequence of Pareto perfect equilibria that yield an agreement at the initial price. In these agreements each player receives an allocation in the interval 
$[.33,2]$, which yields profits that are at least as large as what bidders could receive with probability 1 at price $p_{9}=1.9$. In particular, the unique symmetric equilibrium of this game is such that each player bids 1 at the first round, yielding profits of 1.5 .

Further, if only one of the bidders bids strategically, then it is easy to see that he maximizes profits by reaching the same agreement as in a competitive equilibrium at price $p_{10}=2$ and receiving 1 unit. Nevertheless, we will test proposition 1 further by considering the case where this unique strategic player is larger than the remaining competitive players.

The more interesting cases, though, are the intermediate ones. For example, we consider the case where only players $a$ and $b$ can learn how to play. Here, these two players face an upward sloping excess supply curve. We can infer that if both bidders agree on bidding .7 at price 1.8 (this would be the prediction of an appropriate version of proposition 1), they will receive strictly higher profits than by reaching an agreement at price 2.0, where both would receive 1 unit of the good. We investigate the ability of players to overcome any myopic behavior.

\subsection{Empirical Results.}

The results of the simulation of the basic model are summarized in figures 3 to 6 . We report the results of the first 50,000 rounds (with intervals of 500 rounds between observations). Although it is not reported in the figures, agents did overshoot in the first 200 rounds and reached agreements a price higher than the competitive solution. In any case the resulting allocations were roughly the competitive allocations (i.e., 1 unit for each bidder). From round 200 on, they consistently reach an agreement sooner in the game, where they receive approximately 1 unit at a consistent lower price. After 500 rounds they start to alternate themselves on receiving amounts higher and lower than the symmetric equilibrium and roughly after 10,000 rounds they start reaching an agreement at price 1.2. (See figure 3).

While some bidders fare better than others at each round (except player $b$ whom after doing poorly in the beginning detaches himself 
from the other players by doing extremely well ${ }^{7}$ ), they alternate themselves on getting the larger shares. This is our first important result: players learn how to play in relative few rounds. (See figures 4-a to 4-e). Although they cannot exactly coordinate their bids so that they can always receive the symmetric strategic allocations (this is due to the mutation process nature), they appear to be coordinating in the sense of taking turns in bidding larger amounts. These results are consistent with the theoretical predictions of Menezes (1993-a,b).

Figures 5-a to 5-e show the amount of profits made by each bidder. Their strategies usually yield higher profits than the competitive benchmark. (The dotted line indicates the amount of profits the obtained in competitive case). Consequently, the auctioneer's total revenue falls as the game evolves (see figure 6) and bidders are able to extract most of the surplus. This is our second important conclusion. Table 1 confirms that on average every bidder fares better following their evolutionary strategies then when all play their competitive strategies.

\section{Table 1.}

Average bid/profit for the first 50,000 rounds

(with intervals of 500 rounds between observations)

\begin{tabular}{lrrrrr}
\hline & Player $a$ & Player $b$ & Player $c$ & Player $d$ & Player $e$ \\
bids & .69 & 1.42 & .79 & .67 & .38 \\
profits & .91 & 1.16 & 1.01 & .87 & .52 \\
\hline
\end{tabular}

Next we examine various modifications of the basic model, such as changes in the rate of mutation, changes in the bidders' probability of mutating, distinct initial conditions and bidders with non-adaptive

\footnotetext{
${ }^{7}$ Obscrve that program associates a scquence of random numbers to each player, and based on these numbers and on relative profits they change their bchavior. Thus, at some point Player $b$ drew the right random number and received a large amount of profits. Given the structure of the gamc, his high relative profits reduces his chance of changing. In fact, after 100,000 rounds his allocation is reduced to .15 .
} 
behavior.

\section{a) Changes in the rate of mutation}

We now consider the effects of having a substantially higher mutation rate of 0.1 . This allows us to examine two things. First, we can observe within a smaller number of rounds players alternating themselves on receiving the highest awards, since the speed of the adaptive process is increased. We can also check that players converge to the symmetric equilibrium faster but they still behave randomly after a certain number of rounds. Second, this introduces some inflexibility on bidders behavior. For instance, this mutation rate may induce a change of behavior amounting to a large fraction of the original bid. We expect that this may induce some non-optimal behavior.

Figures 7-a to 7-e describe the evolution of players' behavior in the first 10,000 rounds (again with intervals of 500 rounds between observations). The equilibrium price reaches 1.2 within the first 100 rounds. Thus, the auctioneer, total revenue decreases faster than before and bidders are able to extract much of the trading surplus. In this case it is evident that players present a cycling behavior, and that they take turns on receiving the highest awards. Table 2 shows that they continue to fare better than the competitive benchmark.

\section{Table 2.}

Average bid/profit for the first 10,000 rounds

(with mutation $=0.1$ )

\begin{tabular}{lrrrrr}
\hline & Player $a$ & Player $b$ & Player $c$ & Player $d$ & Player $e$ \\
bids & .71 & 1.19 & .96 & .48 & .63 \\
profits & .85 & 1.21 & 1.01 & .57 & .67 \\
\hline
\end{tabular}

Note that Player $b$ is still performing better on average, but this is due to his good performance in the beginning of the game, since his share of the total supply is already decreasing before the 10,000 th round. In fact, he receives 0 at both the 20,000th and 30,000th rounds. 
Further, after 20,000 rounds the equilibrium price increases to 1.5 and it remains around this level after that. (In fact it is 1.5 at the 50,000 th round, 1.6 at the 150,000 th round, and 1.5 at 20,000 th round!). Hence, there is some lack of coordination between players because they always adjust their bids by a large amount.

\section{b) Players mutate with a higher probability}

We also tested the robustness of our result that players tend to accommodate each other's bids and that an agreement is reached sooner than in the competitive benchmark with respect to changes in the player's probability of mutating. Specifically, we consider that a bidder changes his bid whenever his associated random number is greater than or equal to twice the amount of relative profits. ${ }^{8}$ For instance, after the initial round, each bidder mutates with probability .6.

Agreement prices behave in the same fashion as in the original model. Some overshooting happened in the first 100 rounds and the price reached 2.3 with bidders receiving approximately 1 unit each. However after the 200th round prices start to fall and they submit bids close to the symmetric equilibrium. After 500 rounds they start to move from the symmetric allocations and prices continue to decline, reaching the 1.2 level around round 9,000th. Prices remain at that level until round 30,000, when it reached 1.1 After 200,000 rounds the equilibrium price was still 1.1.

Figures 8-a through 8-e show the evolution of players' behavior in the first 10,000 rounds. Apparently players alternate themselves on receiving the highest and lowest awards, and this behavior is consistent with the results of playing the game strategically, since it yields strictly lower agreement prices and profits that average higher than the competitive benchmark Table 3 below provides the average bids and profits for the first 10,000 rounds with intervals of 500 rounds between observations. Notice how close the average bids are to the symmetric strategic behavior benchmark.

${ }^{8}$ We also run the program assuming that players mutate whenever their associated random numbers are greater than or equal to their relative profits. However, this induces a very high probability of mutating, yielding inconsistent results. 
Flávio Marques Menezcs

Table 3.

Average bid/profit for the first 10,000 rounds

(with higher probability of mutation)

\begin{tabular}{lrrrrr}
\hline & Playcr $a$ & Playcr $b$ & Playcr $c$ & Playcr $d$ & Player $e$ \\
bids & .85 & .75 & .81 & .76 & .73 \\
profits & .95 & .85 & .92 & .83 & .80 \\
\hline
\end{tabular}

\section{c) The direction of mutation is biased downward}

We now examine the effects of having players with a higher probability to reduce than to increase their bids once they are required to mutate. As expected, this restriction induces bidders to behave so that the agreement price converges to 1 very quickly (in less than 700 rounds). At that point bidders are very close to the symmetric strategic benchmark. However, the downward bias induces bidders to further decrease their bids so that some of them end up receiving 0 unities while others receive 1 or more unities at a price equal to 1 . Even in this instance, they alternate themselves on receiving these distinct awards.

\section{d) Players start with distinct initial behavior}

We now examine the effects of having players start bidding from a different region in the parameter space. Specifically, we consider the possibility that players may start using their symmetric strategic equilibrium bids (e.g., they bid 1 for each price less than or equal to 2 , and their demands thereafter). Table 4 summarize the results under five distinct regimes.

Observe that the payoffs of the players who start bidding their symmetric strategic equilibrium bids increase as the number of bidders behaving this way increases. Further, although this behavior may yield an initial advantage to those who start playing competitively, this advantage is dissipated with the repetition of the game. Finally and more important, when each player's initial bid is given by the symmetric strategic benchmark, individuals' profits are strictly higher than in the case where they all starting playing their competitive strategy. (With the exception of the 10,000 th round). 
Strategic behavior in ascending-price auctions

Table 4.

Equilibrium bids and profits under distinct regimes (100th round)

\begin{tabular}{|c|c|c|c|c|c|}
\hline $\begin{array}{l}\text { Regime/ } \\
\text { Price }\end{array}$ & $\begin{array}{r}\text { Player a } \\
\text { Bids/ } \\
\text { Profit }\end{array}$ & $\begin{array}{r}\text { Player } b \\
\text { Bids/ } \\
\text { Profits }\end{array}$ & $\begin{array}{r}\text { Player c } \\
\text { Bids/ } \\
\text { Profits }\end{array}$ & $\begin{array}{r}\text { Player } d \\
\text { Bids/ } \\
\text { Profits }\end{array}$ & $\begin{array}{r}\text { Player } e \\
\text { Bids/ } \\
\text { Profits }\end{array}$ \\
\hline $\mathrm{I} / 2.0$ & $.81 / .48$ & $.96 / .5$ & $1.02 / .5$ & $.98 / .5$ & $1.04 / .5$ \\
\hline II $/ 1.9$ & $.81 / .56$ & $.75 / .54$ & $1.12 / .6$ & $1.01 / .6$ & $1.06 / .6$ \\
\hline III/1.8 & $.83 / .65$ & $.77 / .63$ & $.8 / .64$ & $1.28 / .72$ & $1.17 / .78$ \\
\hline $\mathrm{IV} / 1.5$ & $.83 / .9$ & $.83 / .9$ & $.86 / .92$ & $.83 / .9$ & $1.49 / 1.12$ \\
\hline $\mathrm{V} / 1.1$ & $1.01 / 1.41$ & $.98 / 1.38$ & $.9 / 1.3$ & $.95 / 1.35$ & $1.0 / 1.41$ \\
\hline \multicolumn{6}{|c|}{ (1000th round) } \\
\hline $\mathrm{I} / 1.7$ & $.01 / .01$ & $1.24 / .84$ & $1.12 / .83$ & $1.27 / .84$ & $1.19 / .84$ \\
\hline II $/ 1.4$ & $.15 / .23$ & $.55 / .73$ & $1.31 / 1.24$ & $1.51 / 1.28$ & $1.32 / 1.24$ \\
\hline III/1.3 & $.48 / .7$ & $.53 / .76$ & $.65 / .89$ & $1.55 / 1.43$ & $1.59 / 1.44$ \\
\hline IV/1.2 & $.73 / 1.05$ & $.74 / 1.06$ & $.69 / 1.0$ & $.63 / .94$ & $1.98 / 1.6$ \\
\hline $\mathrm{V} / 1.1$ & $.73 / 1.12$ & $1.13 / 1.51$ & $.96 / 1.36$ & $.95 / 1.35$ & $1.14 / 1.52$ \\
\hline \multicolumn{6}{|c|}{$(10,000$ th round $)$} \\
\hline $\mathrm{I} / 1.2$ & $.05 / .09$ & $1.61 / 1.6$ & $1.54 / 1.59$ & $1.31 / 1.5$ & $.15 / .26$ \\
\hline II/1.3 & $0 / 0$ & $.39 / .59$ & $1.22 / 1.33$ & $1.09 / 1.26$ & $1.26 / 1.35$ \\
\hline III/1.2 & $.06 / .11$ & $1.02 / 1.32$ & $0 / 0$ & $1.49 / 1.57$ & $1.77 / 1.62$ \\
\hline IV $/ 1.1$ & $.14 / .26$ & $1.35 / 1.65$ & $.48 / .8$ & $.01 / .02$ & $1.91 / 1.8$ \\
\hline $\mathrm{V} / 1.0$ & $.45 / .8$ & $1.34 / 1.78$ & $1.03 / 1.53$ & $.87 / 1.36$ & $.02 / .04$ \\
\hline \multicolumn{6}{|c|}{ (100,000th round) } \\
\hline $\mathrm{I} / 1.2$ & $.28 / .46$ & $.42 / .67$ & $1.18 / 1.43$ & $.35 / .57$ & $.13 / .23$ \\
\hline II/1.1 & $.4 / .68$ & $.32 / .56$ & $1.34 / 1.65$ & $.37 / .63$ & $.42 / .71$ \\
\hline III/1.1 & $.42 / .71$ & $1.31 / 1.63$ & $.79 / 1.19$ & $.45 / .75$ & $.5 / .83$ \\
\hline IV/1.2 & $.43 / .68$ & $.06 / .11$ & $1.2 / 1.44$ & $1.63 / 1.61$ & $.13 / .23$ \\
\hline $\mathrm{V} / 1.1$ & $.42 / .71$ & $1.31 / 1.63$ & $.79 / 1.19$ & $.45 / .75$ & $.5 / .83$ \\
\hline
\end{tabular}

Regime I: only player a starts bidding his symmetric strategic equilibrium bid Regime II: same for players $a$ and $b$

Regime III: same for players $a, b$ and $c$

Regime IV: same for players $a, b, c$ and $d$ Regime V: same for all five players 
e) The effects of relaxing the monotonicity property

We also test our conjecture that the constraint requiring the sequence of bids to be non-increasing is not bidding. As we relax this hypothesis in our simulation, bidders behave so that they induce the amount of total profits to reach zero within the first 250 round. That is, this monotonicity property is in fact crucial to the determination of players' behavior.

f) Results when four or fewer players can adjust their bids

CASE 1: Only Player $a$ never changes his bids

Figure 9 -a shows the evolution of prices in the first 10,000 rounds. Bidders' behavior is such that as the number of rounds increases, an agreement is reached sooner in the game. For instance, after 100 rounds players reach an agreement at price 1.2. Figures 9-b to 9-e show the evolution of players' bids against the excess supply, i.e., total supply minus Player $a$ 's bid. Players accommodate Player $a$ 's demand and the other players' bids. Table 5 reports the average bid/profits for players $b$ to $e$ in the first 10,000 rounds (with intervals of 500 rounds between observations.

Table 5 .

Average bid/profit for the first 10,000 rounds

(only Player $a$ never changes his bids)

\begin{tabular}{lrrrr}
\hline & Player $b$ & Player $c$ & Player $d$ & Player $e$ \\
bids & .6 & .49 & 1.01 & 1.0 \\
profits & .6 & .46 & .96 & .91 \\
\hline
\end{tabular}

CASE 2: Players $a$ and $b$ never change their bids

Even when two players cannot modify their bids, the remaining bidders find more profitable to accommodate their demands and to reach an agreement sooner. In figures 10-a we describe the evolution of prices, while in figures $10-\mathrm{b}$ to 10 -d we plot the evolution of bidders $c, d$ and $e$ against excess supply. Table 6 reports the average bids/profits for the first 10,000 rounds. 
Stratcgic behavior in ascending-pricc auctions

Table 6.

Average bid/profit for the first 10,000 rounds

(Players $a$ and $b$ never change their bids)

$\begin{array}{lrrr}\text { bids } & \text { Playcr } c & \text { Playcr } d & \text { Playcr } e \\ \text { profits } & .59 & .38 & .58 \\ & .56 & .38 & .6\end{array}$

Observe that players $c, d$ and $e$ still receive a strictly higher profit than by bidding their competitive strategies. In fact, even after 100,000 rounds these players still fare better than their competitive benchmark. (They receive profits of respectively .53, .95 and .59).

CAse 3: Players $a, b$ and $c$ never change their bids

Figure 11 shows the evolution of the bids of Players $d$ and $e$ against the excess supply. Remember that in this case the theory predicts that players will not accommodate each other and that they will settle for the competitive benchmark. However, players try to do so. Player $e$ for instance, receives around .7 in equilibrium during a large number of rounds. Player $d$, on the other hand, starts undershooting and receive substantially less. After a certain number of rounds, though, their relative profits became very low, what induces them to mutate with a higher probability. Given the constraint that bidders cannot increase their bids from one period to another within a particular round, they end up receiving small awards. Nevertheless, the important result is that players $d$ and $e$ try to reach a compromise among themselves on how to divide the excess supply. (We argue that the subsequent undershooting is a result of the monotonicity property, since once mutation brings the initial bids to a number close to zero it may take a long time to observe the sequence of bids to be well above zero again. In fact, if we relax this constraint these two bidders start competing so that an agreement is reached at a price close to 3 or no agreement is reached).

CASE 4: Only Player $e$ changes his bids: for the same reasons of case 3 above, Player $e$ receives approximately 0 units after 3,500 rounds, which indicates an undershooting with respect to the prediction of 
proposition 1. This result also shows that the equilibrium approaches the competitive benchmark as the number of bidders behaving competitively increases. The question then is an empirical one and it is related to the actual composition of markets.

Finally, we reexamine the prediction of proposition 1 by considering a situation where Player $e$ is larger than the remaining participants. Players $a$ to $d$ have the same demand function and Player $e$ has he following demand: $\mathrm{D}(\mathrm{p})=13$ - $\mathrm{p}$. We assume that $T S=15$. The competitive benchmark gives 1 unit to each of the first four bidders and 11 units to Player $e$ at price 2. Player $e$ 's total profits are now 60.5 in the competitive benchmark. Player $e$ is the only one who can change his bids in an adaptive way. To induce the same probability of mutation as before, we consider the case where he mutates whenever his correspondent random number is less than half his relative profits.

Note that he can maximize his profits by accommodating his own demand. For instance after 5,000 round they reach an agreement at price 1.7 , where he receives 62.6 of total profits. After 10,000 rounds he reaches an agreement at price 1.5 and receives 62.6 of profits. After a very large number of rounds, though, for the same reasons stated in case 3 above he starts to make lower profits than his competitive benchmark. Consequently, by making the difference between agents' profits larger we are able to verify that a strategic player does tend to satisfy proposition 1, although this may involve some undershooting.

\section{Conclusions.}

We show, for our ascending-price multiple-object auction, that when a single strategic bidder is playing against many competitive players, he has two options: he either waits to receive his competitive allocation or he accepts a smaller award. He chooses the option that maximizes his profits. We also provide an algorithm to compute a player's optimal bidding strategy in the presence of one-sided uncertainty.

Furthermore, if all players behave strategically, we describe a sequence of coalition-proof equilibria where an agreement is reached at the initial price. When there are two or more players (but not 
all) behaving strategically, then they face an upward sloping supply curve, which may preclude them from trying to reach an agreement sooner in the game.

The results of the simulation indicate several important novel aspects. First, not only players are able to extract most of the trading surplus, but also players may undershoot, decreasing even further the auctioneer's revenue. That is, the equilibrium price decreases in time (and it is very close to the initial price) and total amount bid in equilibrium tends to be less than 5 with bidders alternating themselves on receiving the highest awards.

Second, even in the presence of players who cannot adjust their bids, strategic players are able to accommodate each other. However,as the number of bidders playing strategically decreases, their ability to adjust induces equilibria where they receive very small amounts. In the extreme case when there is only one bidder playing strategically, he undershoots and receives awards close to zero units and many rounds may be needed to overcome such behavior. However, once this player is larger than his opponents, proposition 1 works and he is able to accommodate their demands, reaching an agreement sooner in the game. Our results also highlight the need to study in details the market structure. Finally the results also indicate that the monotonicity property that requires the sequence of bids to be non-increasing plays an important role in explaining bidders' undershooting. It makes upward bid adjustments more difficult to happen. It is interesting to note that such undershooting behavior consistently appears in both laboratory experiments and simulations of the economic theory of auctions.

In all, these results suggest that even in the presence of many small competitive participants, strategic bidders may play the game in such way that an agreement is reached at a price close to the initial one. In these agreements the auctioneer is unable to capture most of the trading surplus. These results strengthen our previous theoretical arguments showing that this mechanism is biased toward the buyers.

(Received March 1993. Revised February 1994) 


\section{References}

Goldberg, D. 1989. Genetic Algorithms in Search, Optimization, and Machine Learning. New York: Addison-Wesley.

Hansen, R.G. 1988. "Auctions with endogenous quantity." RAND Journal of Economics 19:44-58.

Holland, J. 1975. Adaptation in Natural and Artificial Systems. Ann Arbor: University of Michigan Press.

Holland, J. \& J.H. Miller 1991. "Artificial adaptive agents in economic theory." American Economic Review 81:365-370.

Joint Report on the Government Securities Market. January 1992. Washington, D.C.: Department of the Treasury, Securities and Exchange Commission and Board of Governors of the Federal Reserve System.

Marimon, R., E. McGrattan \& T.J. Sargent 1990. "Money as a medium of exchange in an economy with genetically reproduced decision rules." Journal of Economic Dynamics and Control 14: 329-373.

Marimon, R. \& J.H. Miller 1990. "Money as a medium of exchange in an economy with genetically reproduced decision rules." Working Paper, Santa Fe Institute.

Menezes, F.M. 1993-a. "Leilōes de privatização: uma análise de equilíbrio." Revista Brasileira de Economia 47:317-348.

Menezes, F.M. 1993-b. "Ascending-price multiple-object auctions." Working Peper 254, Australian National University.

Milgrom, P. 1987. "Auction theory." In Bewley, T. (ed.) Advances in Economic Theory: Fifth World Congress. Cambridge: Cambridge University Press.

Miller, J.H. \& J. Andreoni 1990-a. "Auctions with adaptive artificially intelligent agents." Working Paper №9032, University of Wisconsin - Madison.

Miller, J.H. \& J. Andreoni 1990-b. "A coevolutionary model of free riding behavior: replicator dynamics as an explanation of the experimental results." Working Paper 9010, University of Wisconsin - Madison.

Wilson, R. 1987-a. "Game-theoretic analysis of trading processes." In Bewley, T. (ed.), Advances in Economic Theory: Fifth World 
Congress. Cambridge: Cambridge University Press.

Wilson, R. 1987-b. "On equilibria of bid-ask markets." In Feiwei, G. R. (ed.), Arrow and the Ascent of Modern Economic Theory. New York: New York University Press.

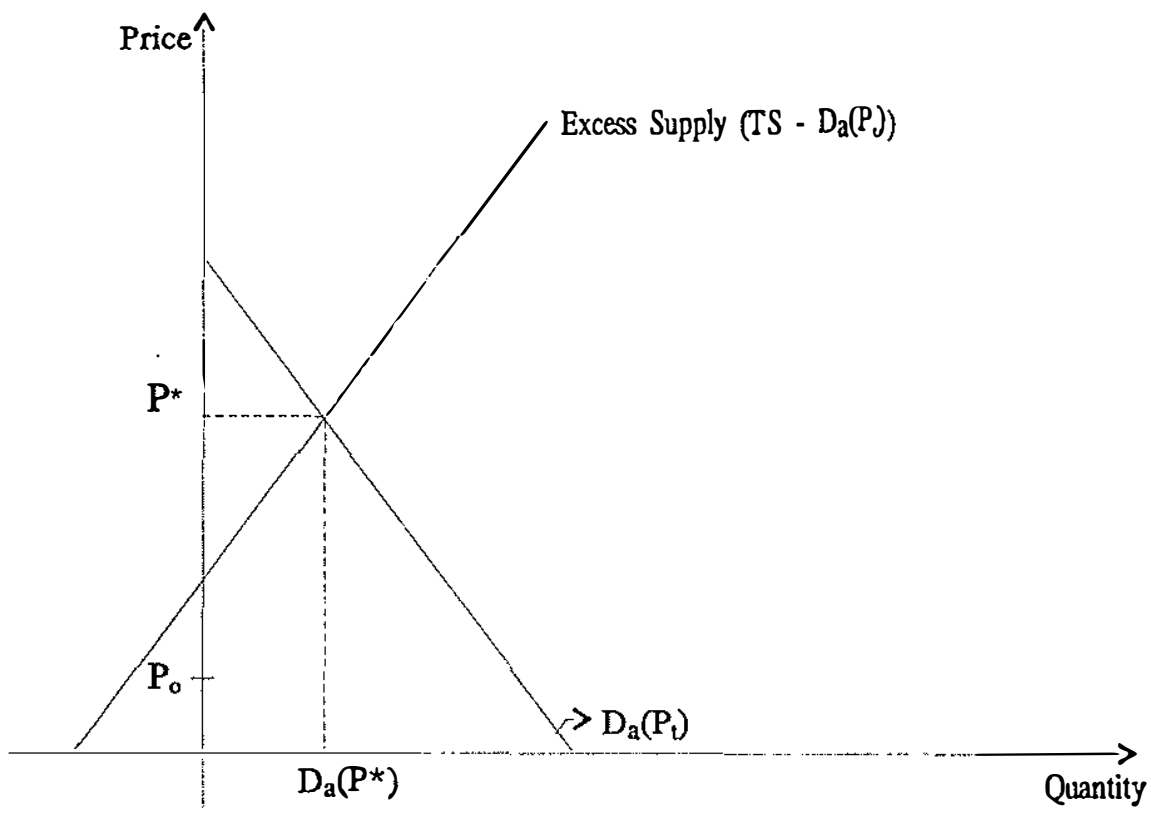

Figure 1. 


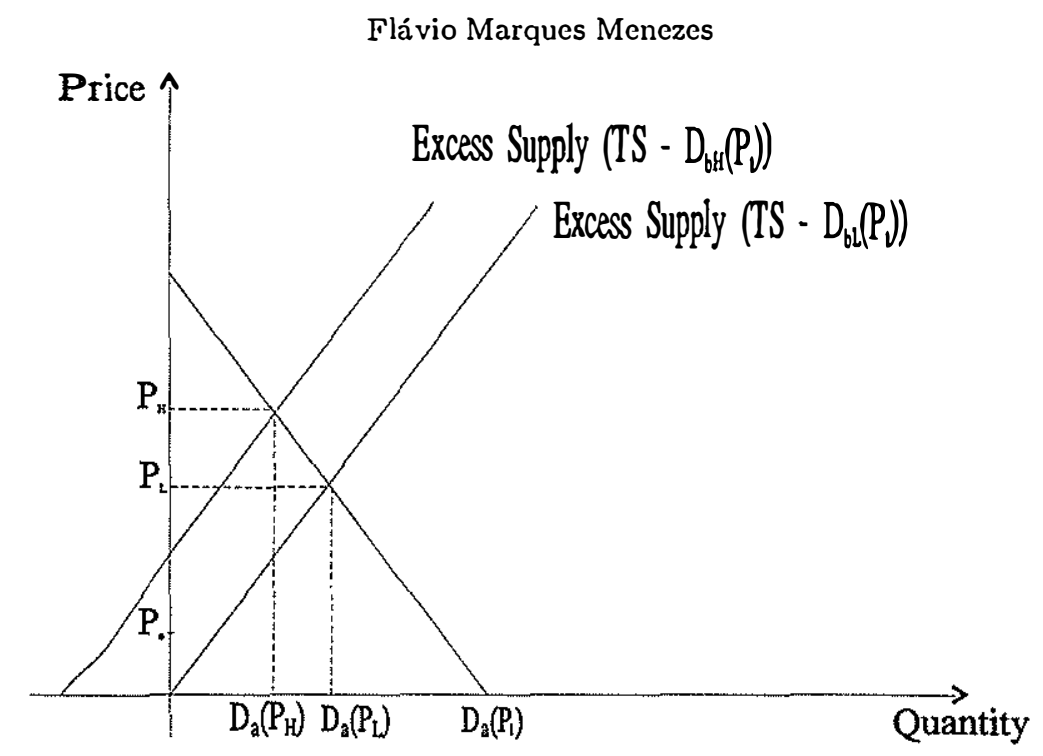

Figure 2.

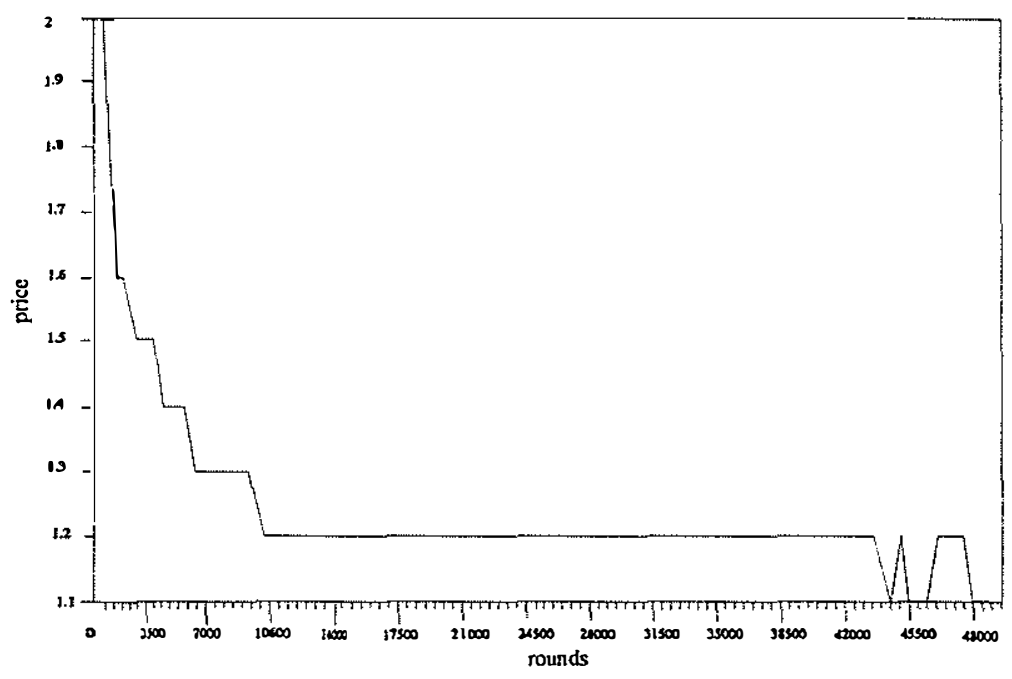

Figure 3.

The evolution of prices 
Stratcgic behavior in ascending-price auctions

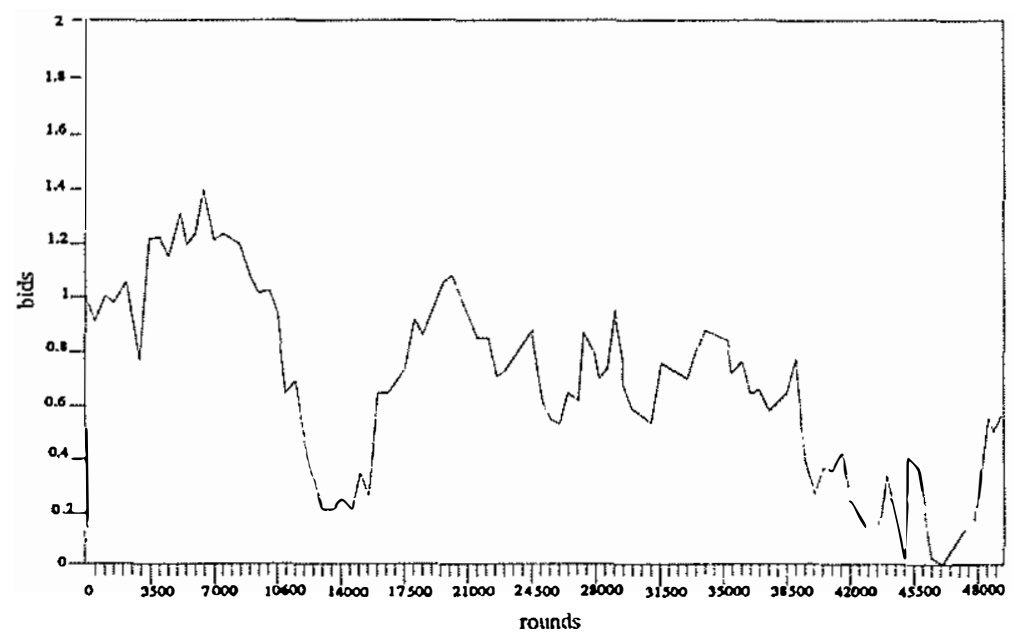

Figure 4-a.

The evolution of player a's behavior

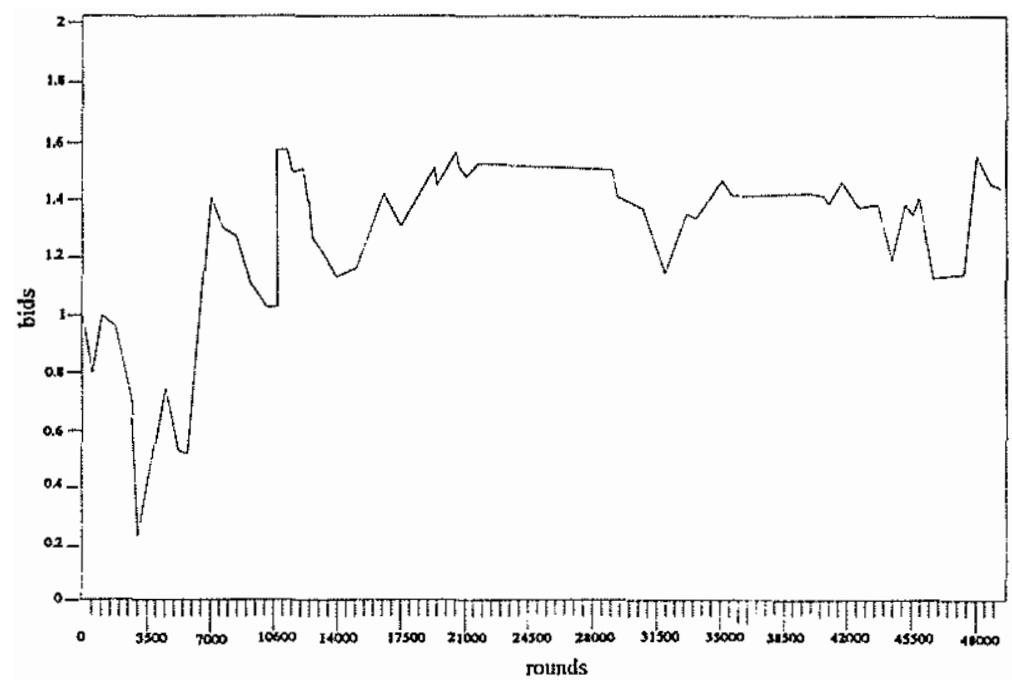

Figure 4-b.

The evolution of player b's behavior 
Flávio Marques Menezes

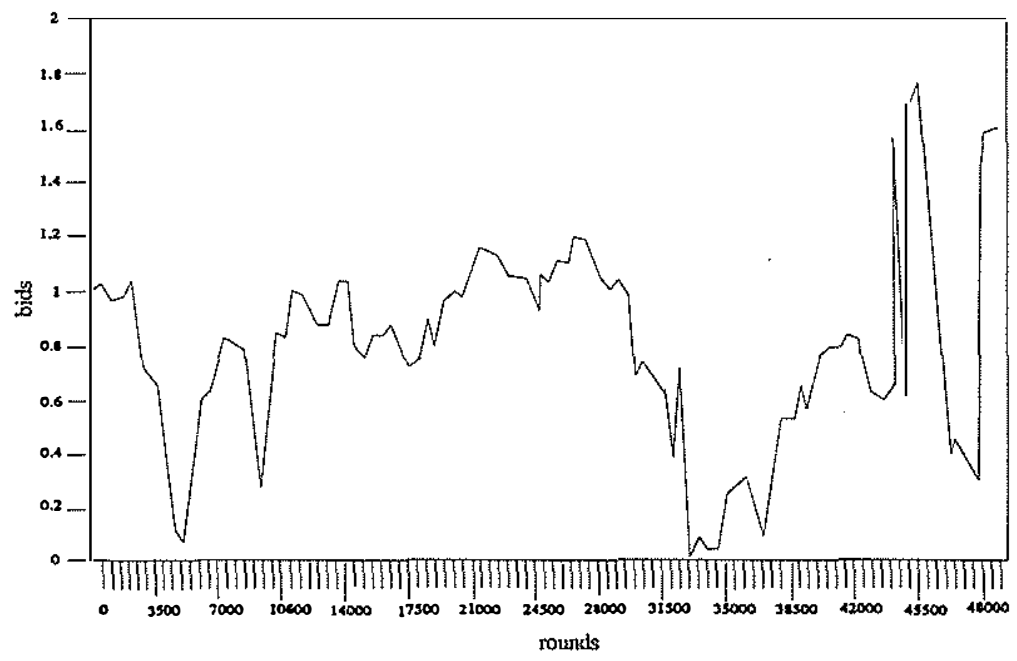

Figure 4-c.

The evolution of player c's behavior

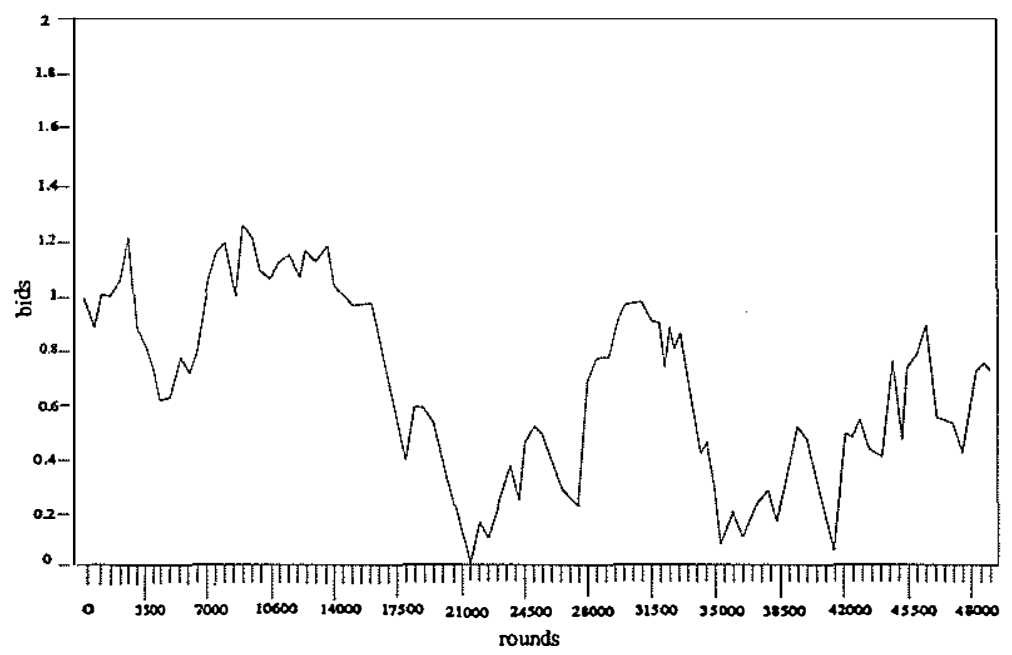

Figure 4-d.

The evolution of player d's behavior 
Strategic behavior in ascending-price auctions

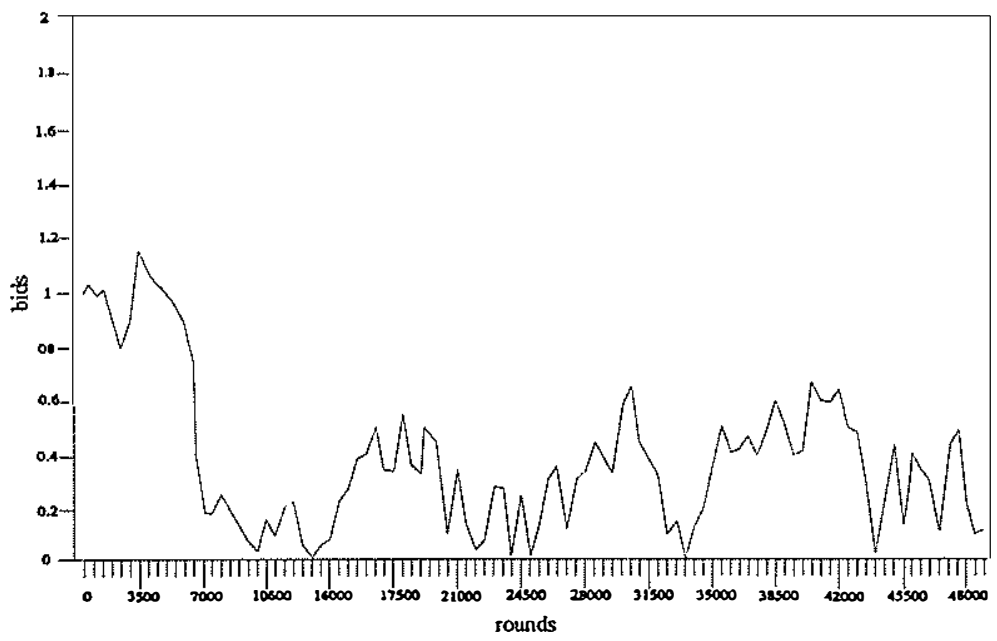

Figure 4-e.

The evolution of player e's behavior

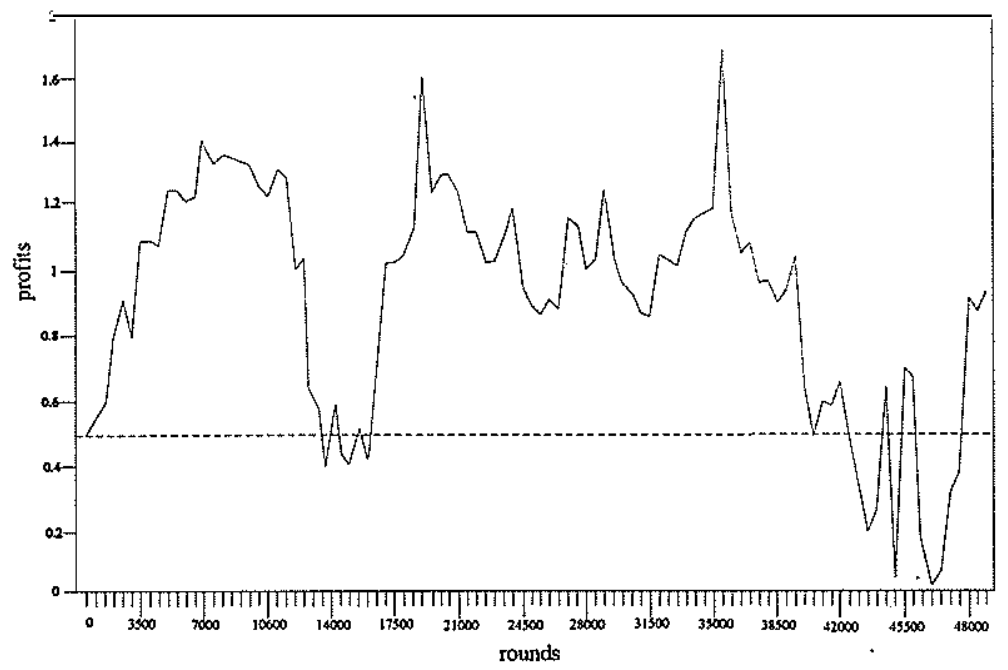

Figure 5-a.

The evolution of a's profits 
Flávio Marques Menezcs

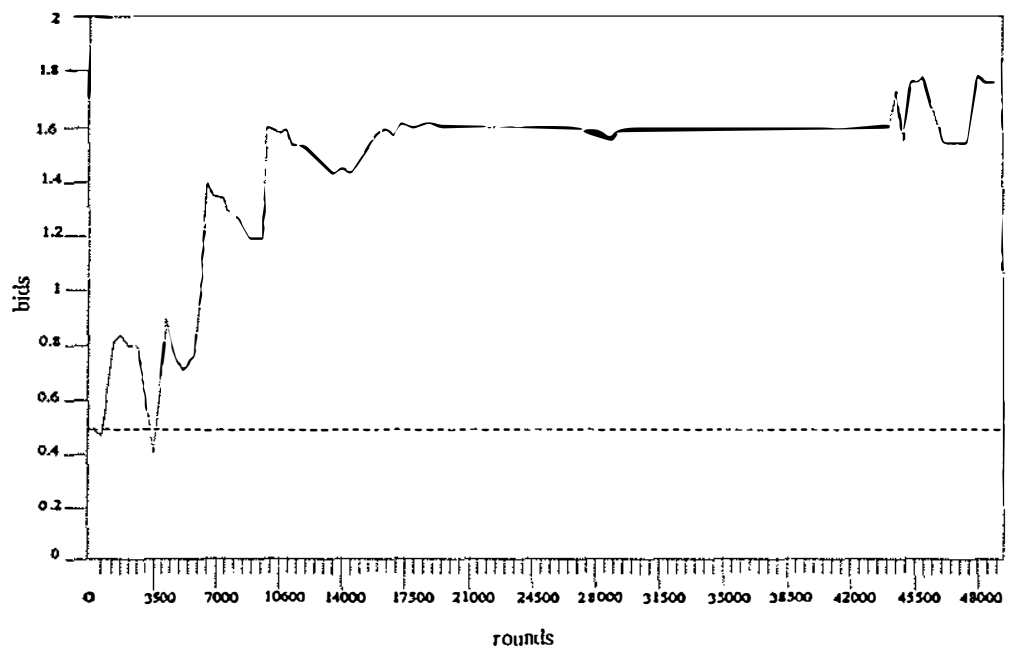

Figure 5-b.

The evolution of b's profits

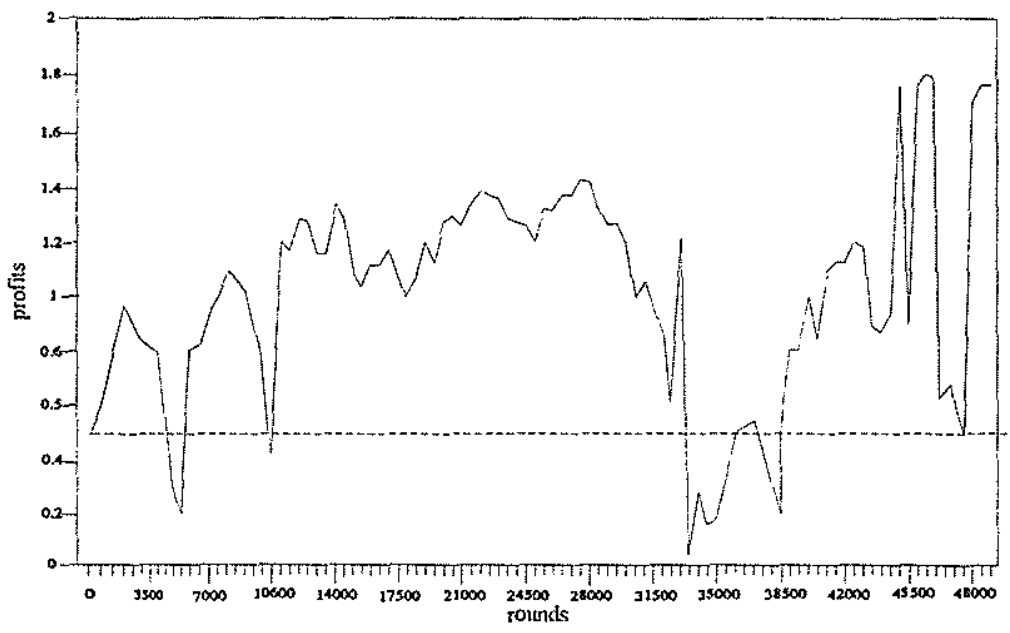

Figure 5-c.

The evolution of c's profits 
Strategic behavior in ascending-price auctions

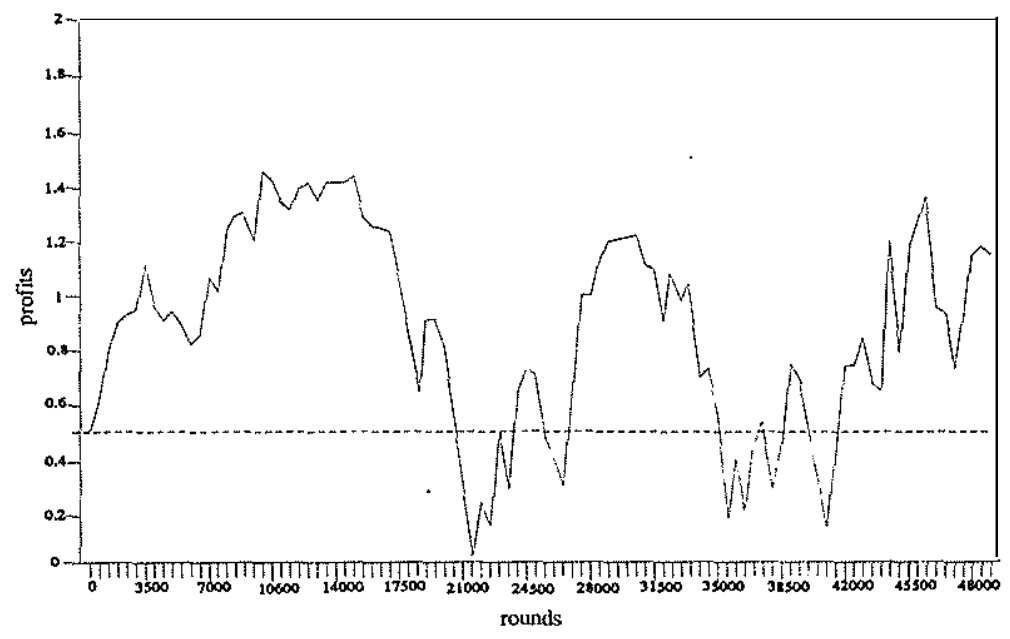

Figure 5-d.

The evolution of d's profits

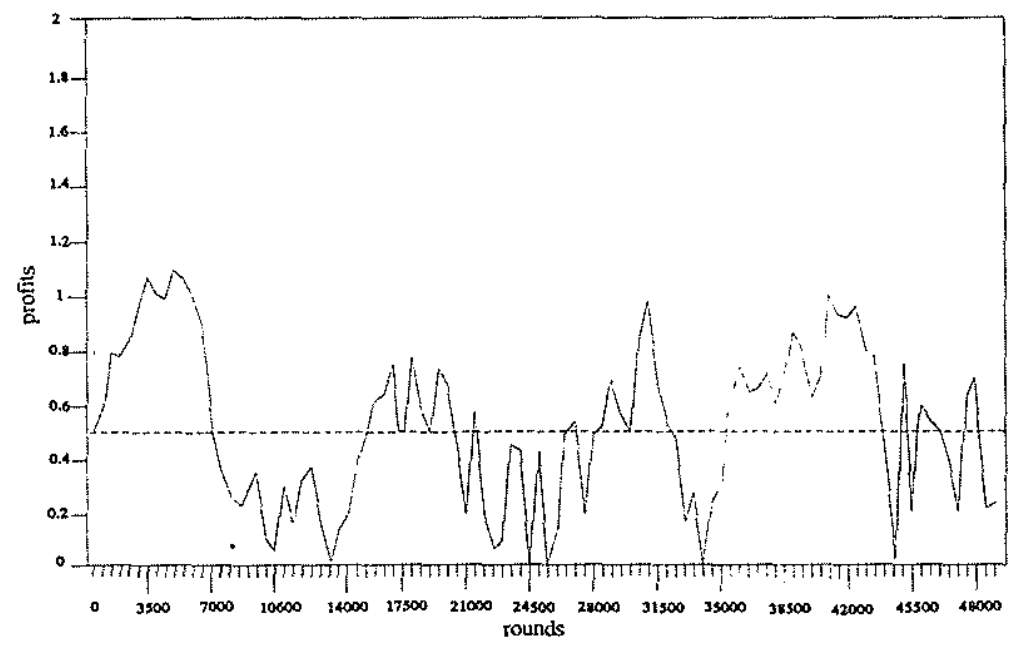

Figure 5-e.

The evolution of e's profits 
Flávio Marques Menezes

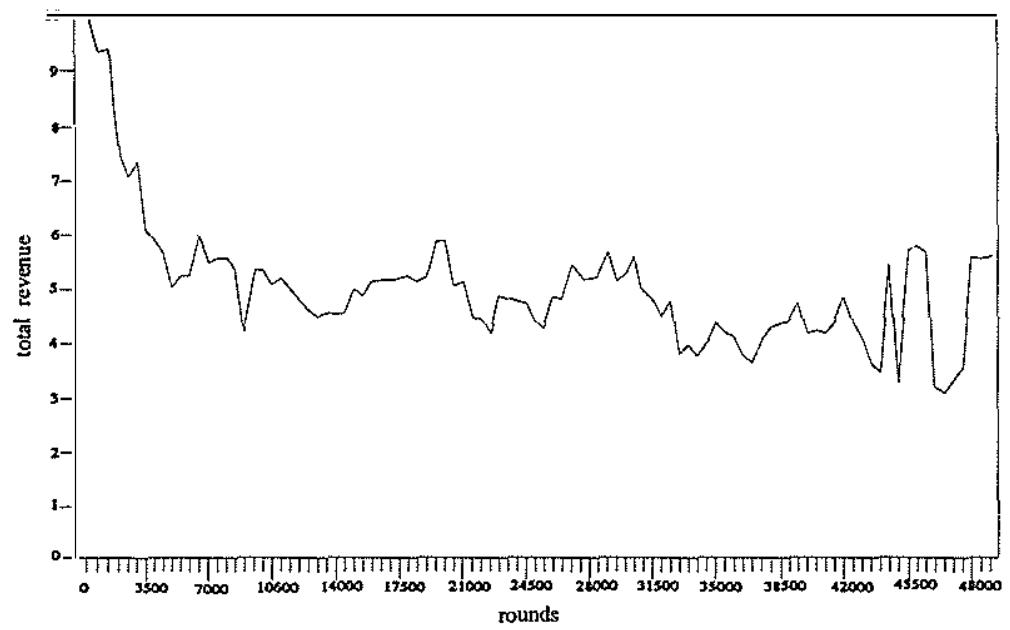

Figure 6.

The evolution of total revenue

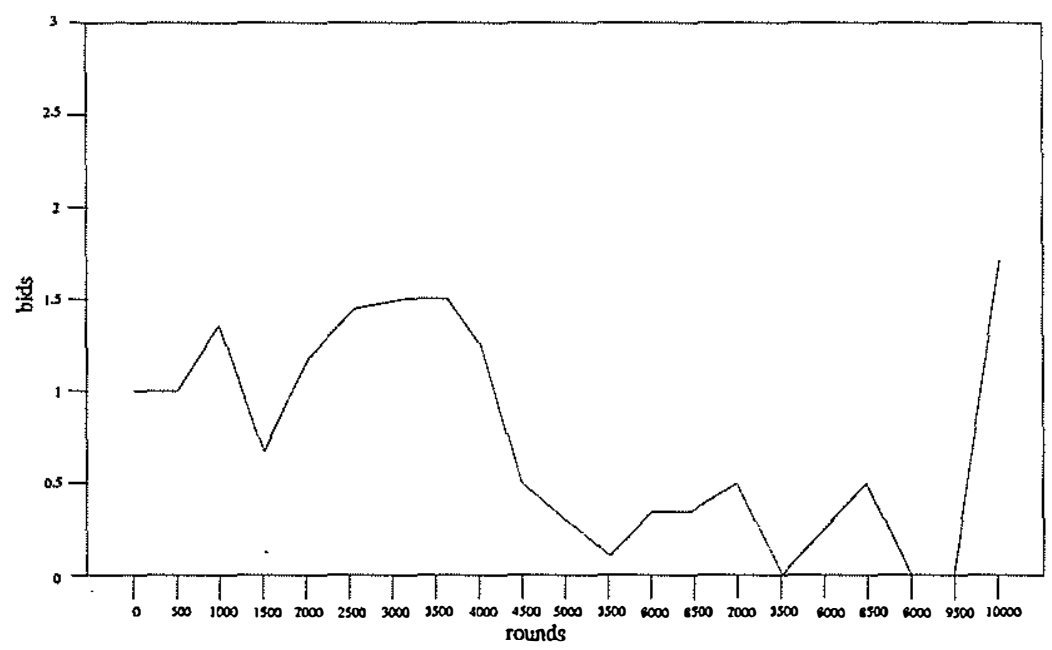

Figure 7-a.

Player a's bids (mut.rate $=.1$ )

R. de Econometria 14(1) abril 1994/outubro 1994 
Strategic behavior in ascending-price auctions

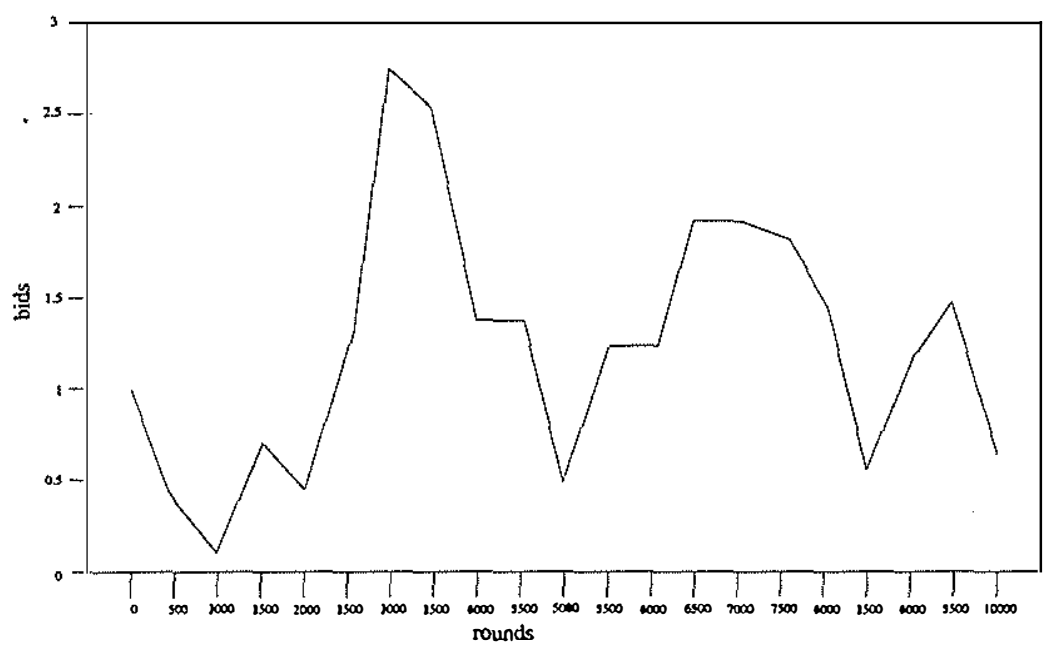

Figure 7-b.

Player b's bids (mut.rate $=.1$ )

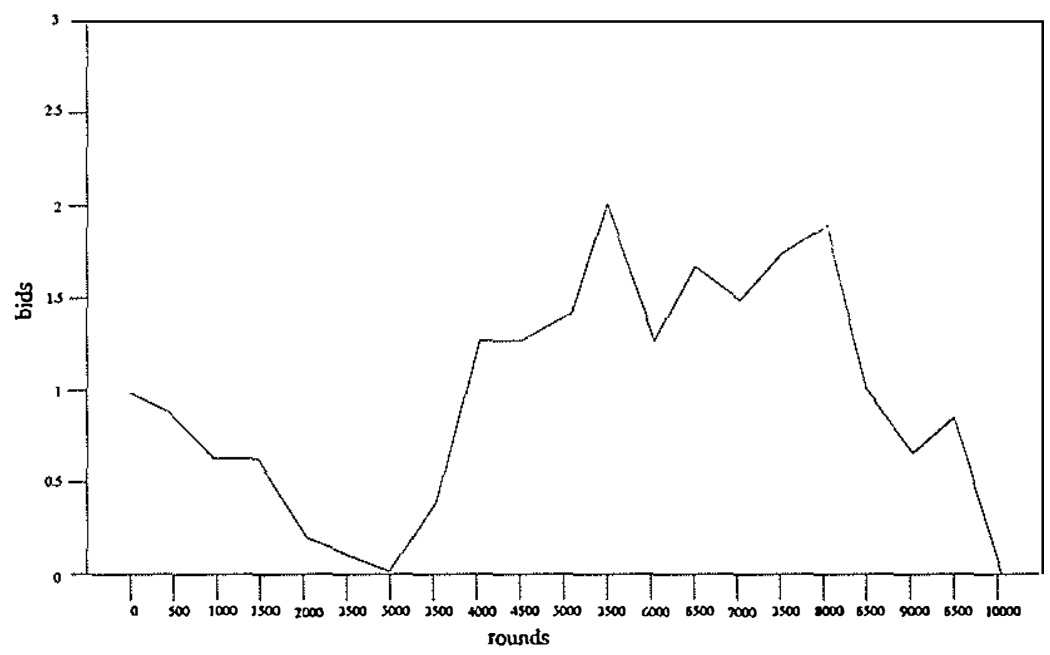

Figure 7-c.

Player c's bids (mut.rate $=.1$ ) 
Flávio Marques Menczes

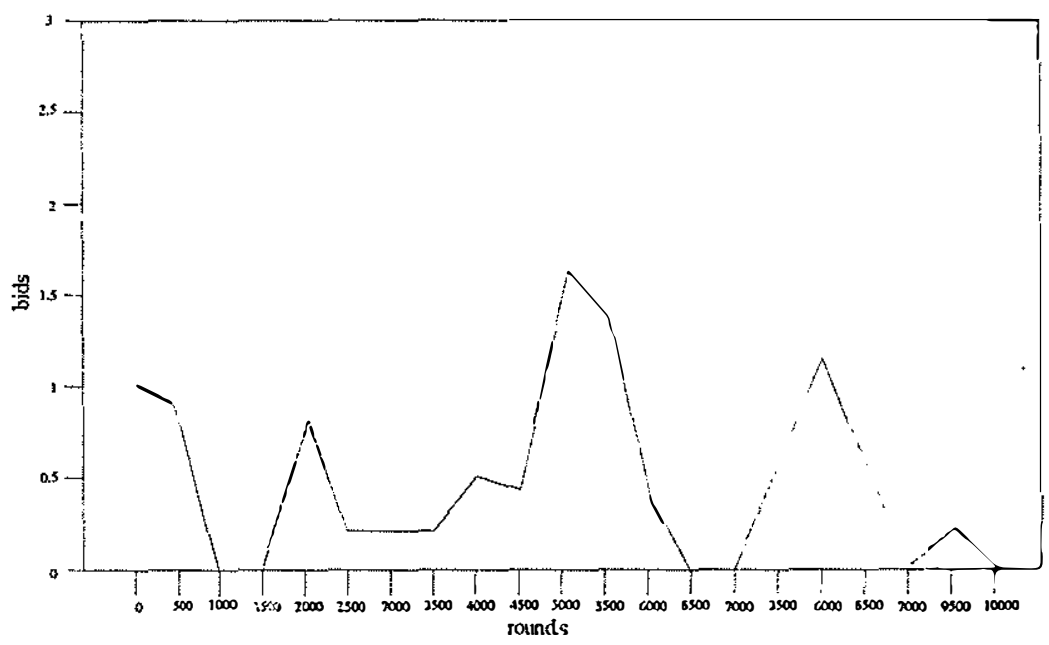

Figure 7-d.

Player d's bids (mut.rate $=.1$ )

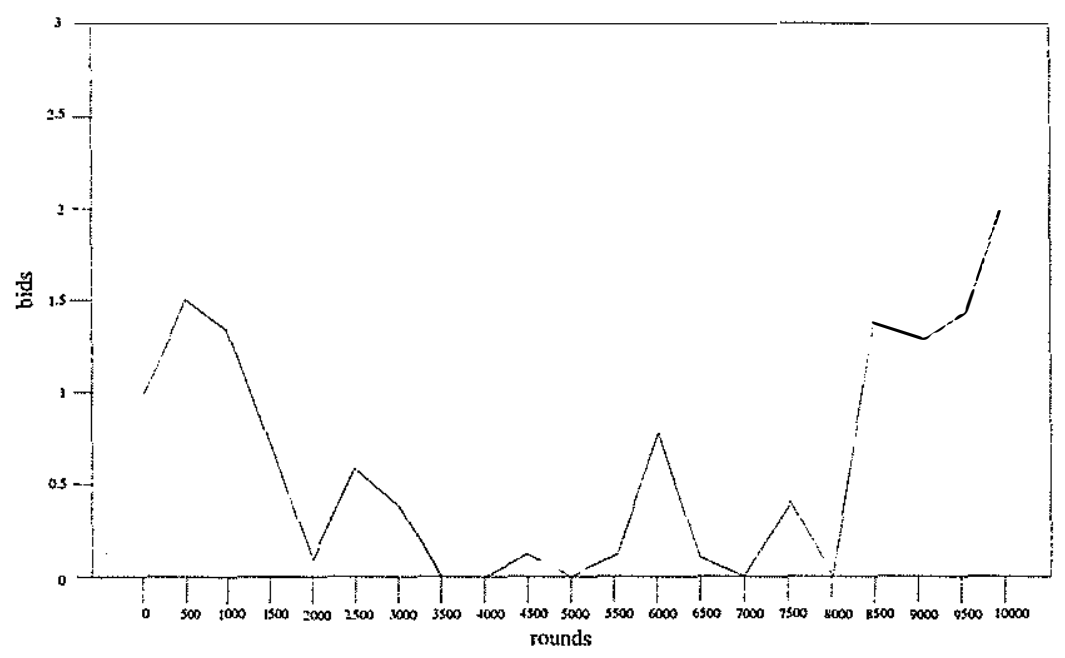

Figure 7-e.

Player e's bids (mut.rate $=.1$ ) 
Stratcgic bchavior in ascending-pricc auctions

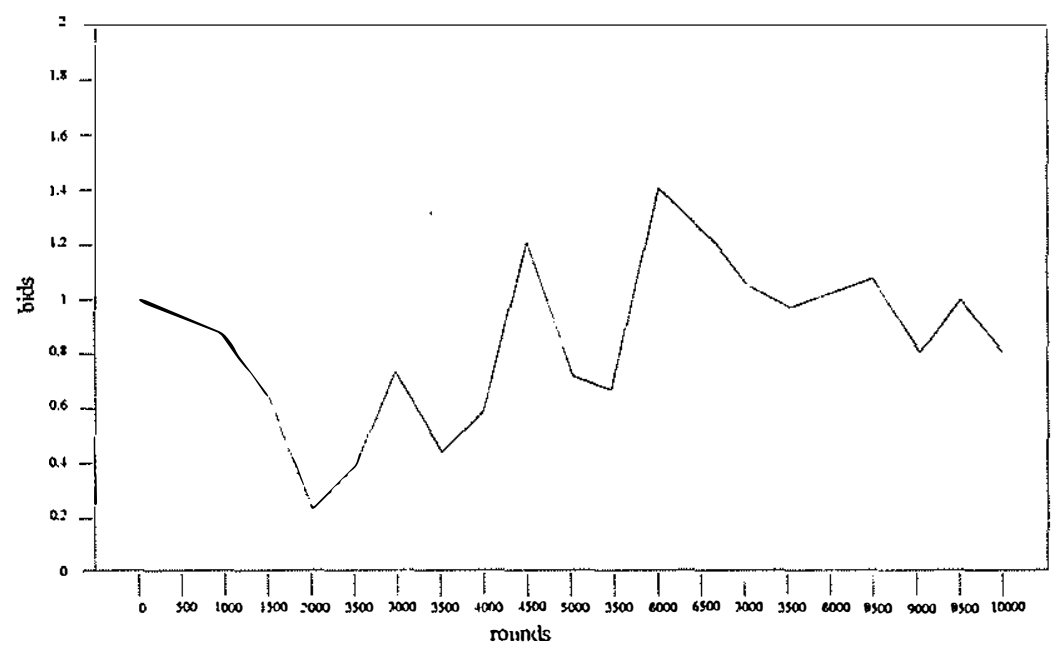

Figure 8-a.

Player a's bids (higher probability of mutating)

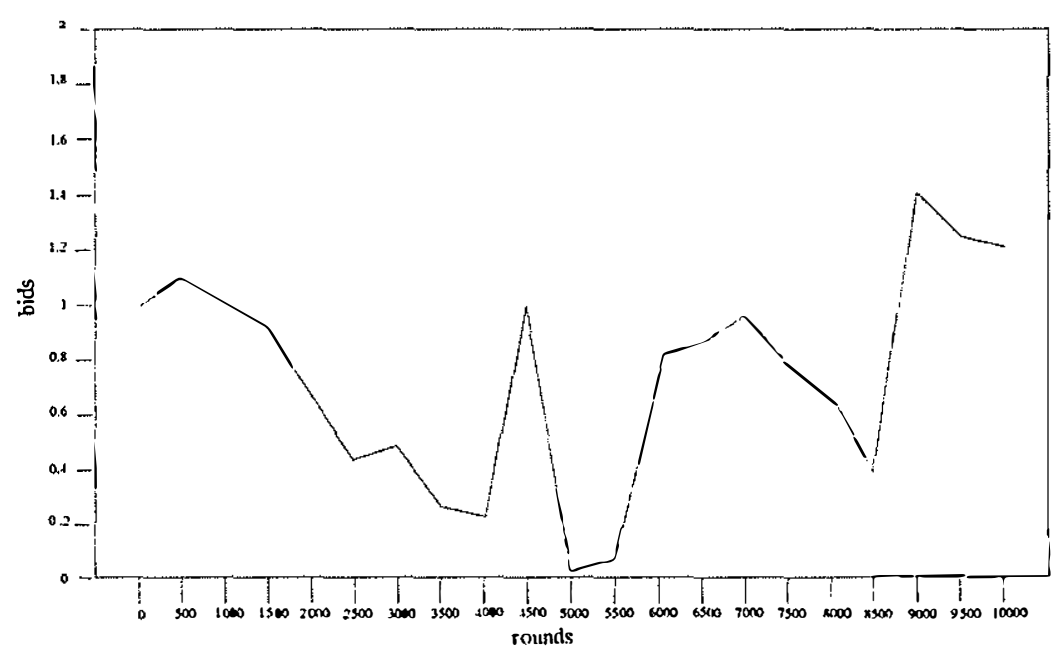

Figure 8-b.

Player b's bids (higher probability of mutating) 
Flávio Marques Menezes

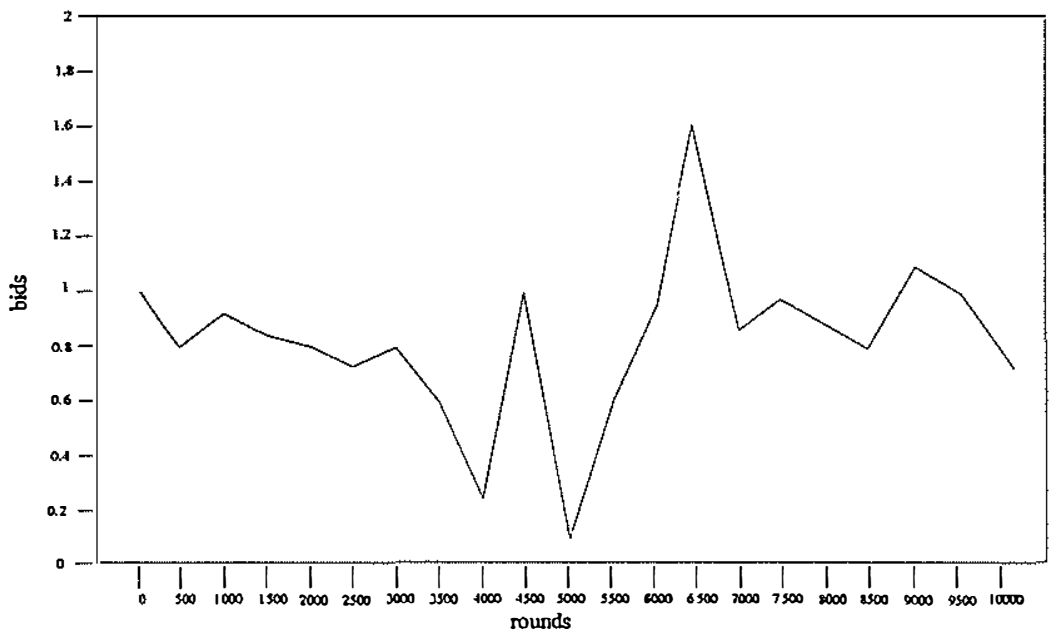

Figure 8-c.

Player c's bids (higher probability of mutating)

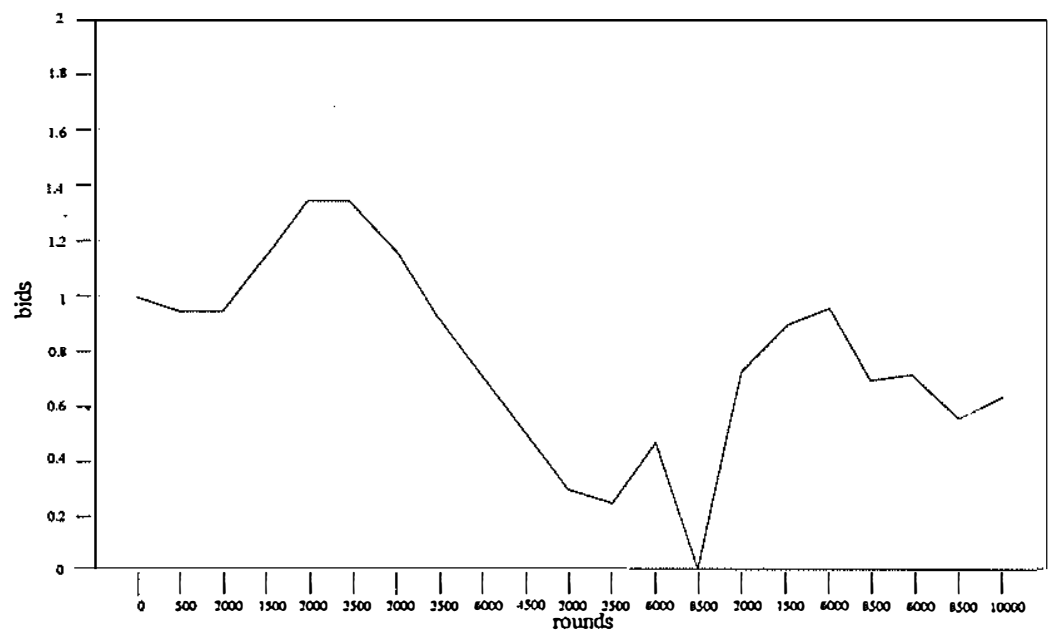

Figure 8-d.

Player d's bids (higher probability of mutating) 
Stratcgic bchavior in ascending-pricc auctions

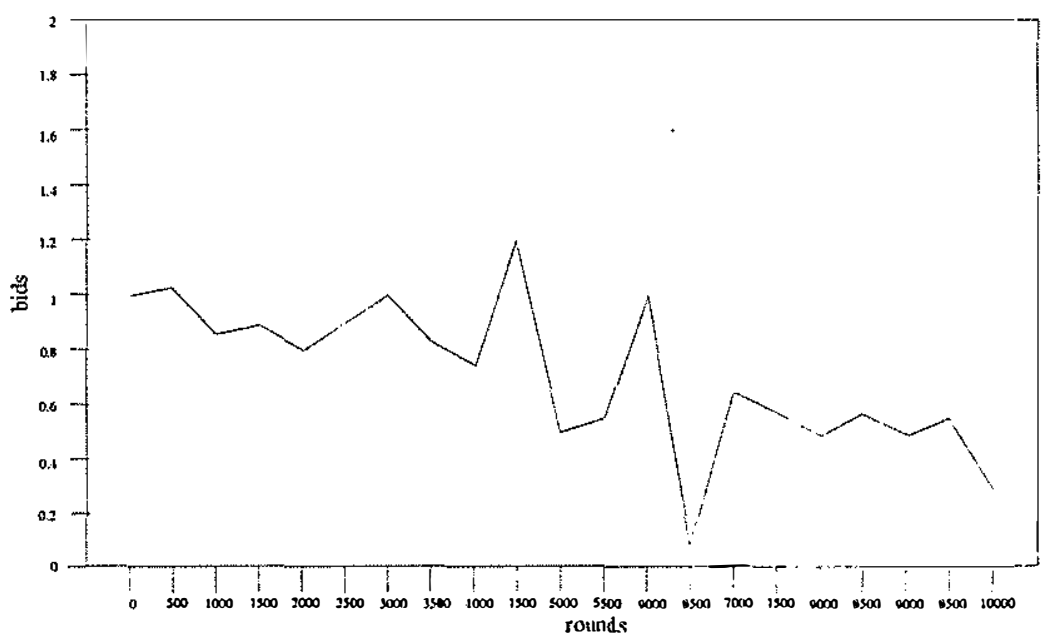

Figure 8-e.

Player e's bids (higher probability of mutating)

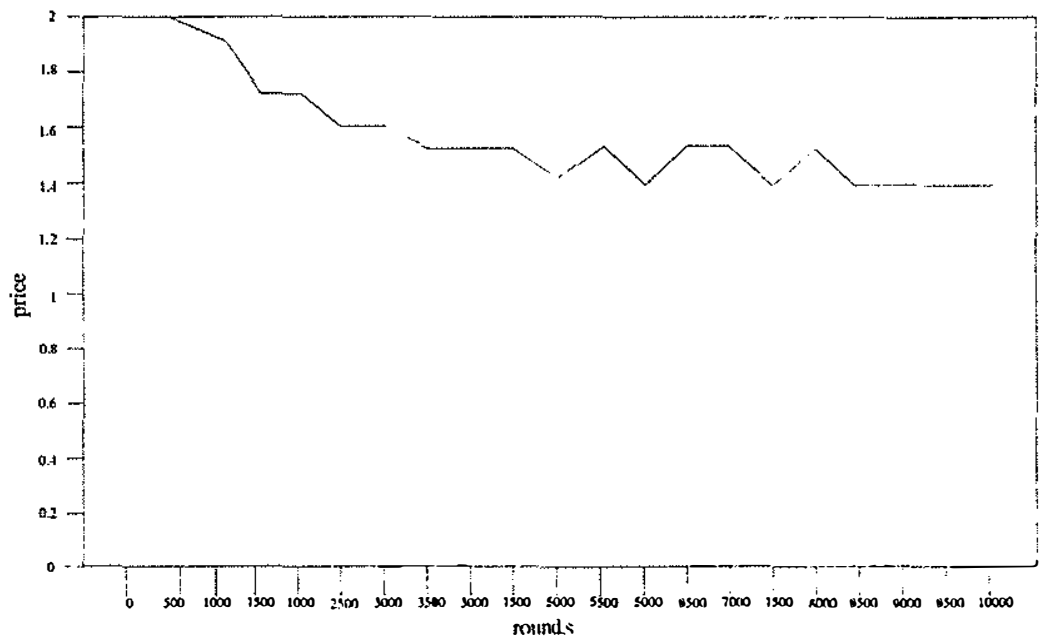

Figure 9-a.

The evolution of prices (player a behaves competitively) 
Flávio Marques Menezes

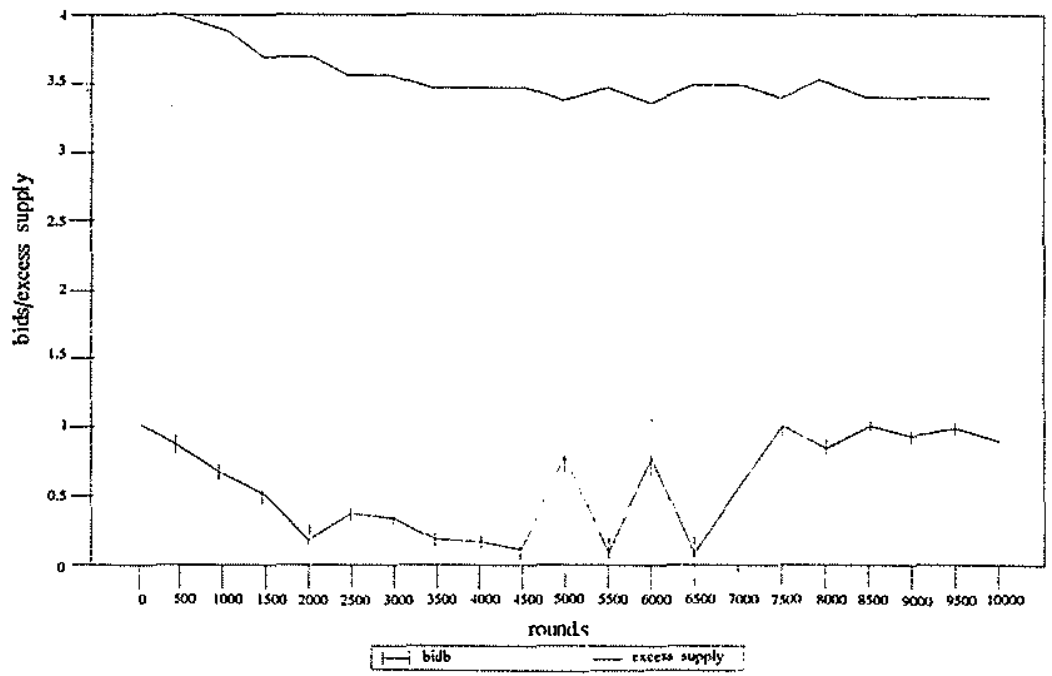

Figure 9-b.

Player b's bids (player a behaves competitively)

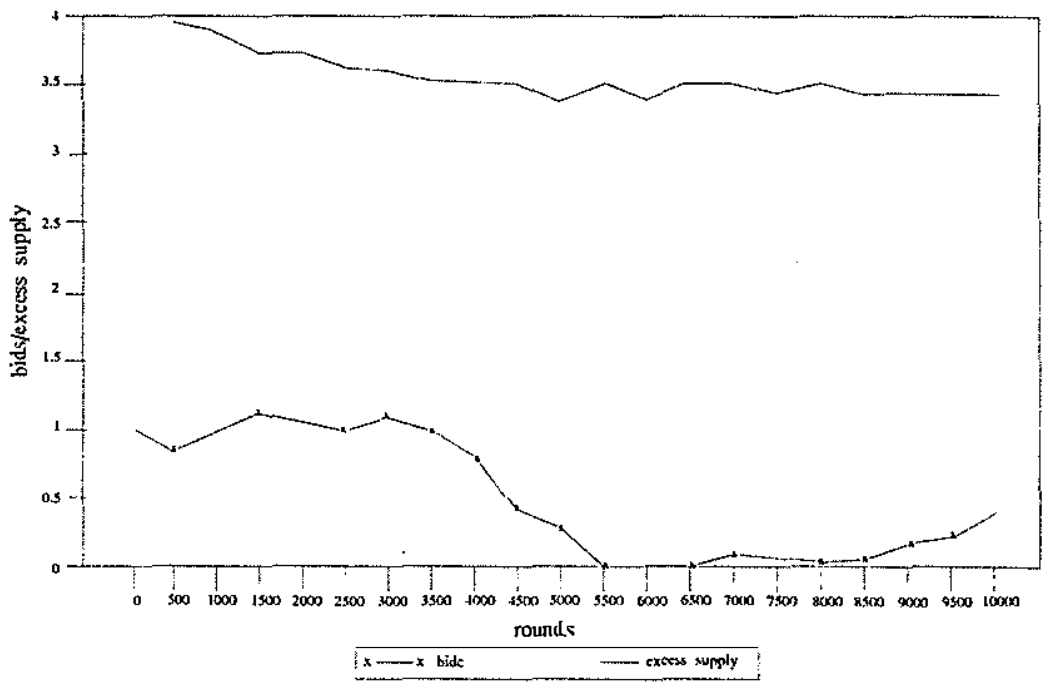

Figure 9-c.

Player c's bids (player a behaves competitively)

R. cle Econometria 11(1) abril 1991/outubro 1991 
Strategic bchavior in ascending-pricc auctions

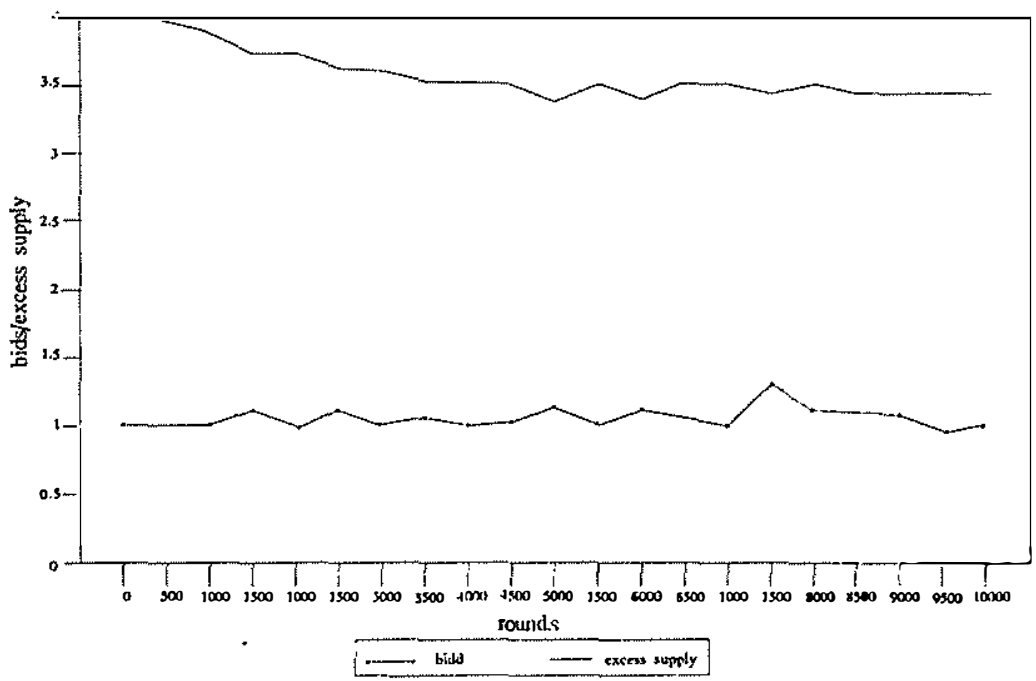

Figure 9-d.

Player d's bids (player a behaves competitively)

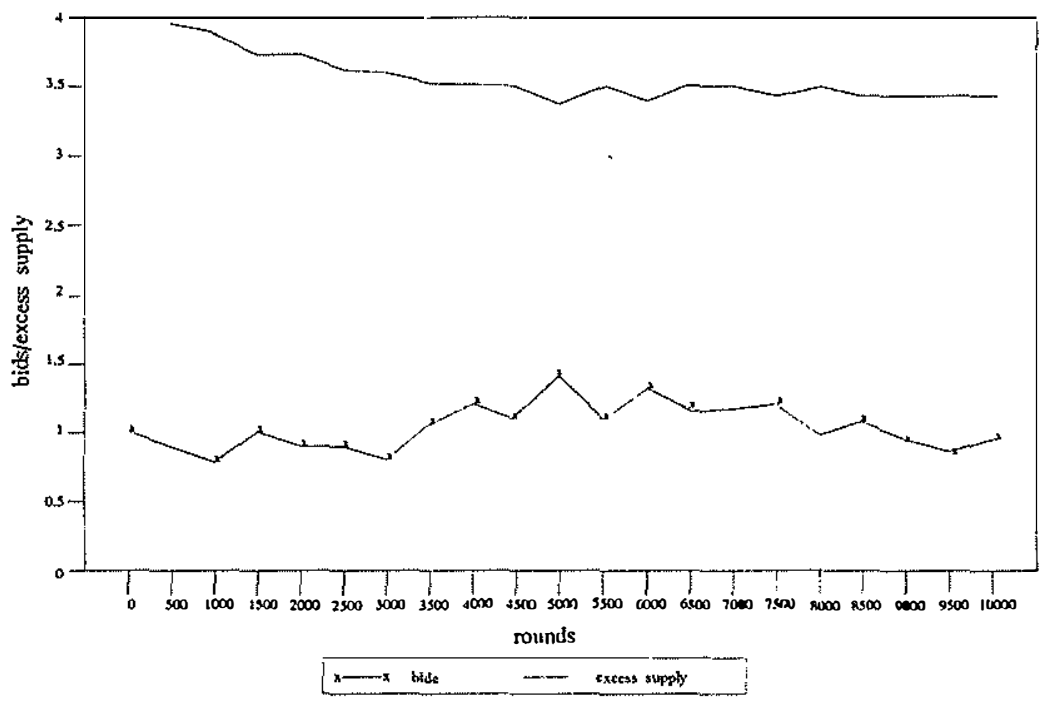

Figure 9-e.

Player e's bids (player a behaves competitively) 
Flávio Marques Menezes

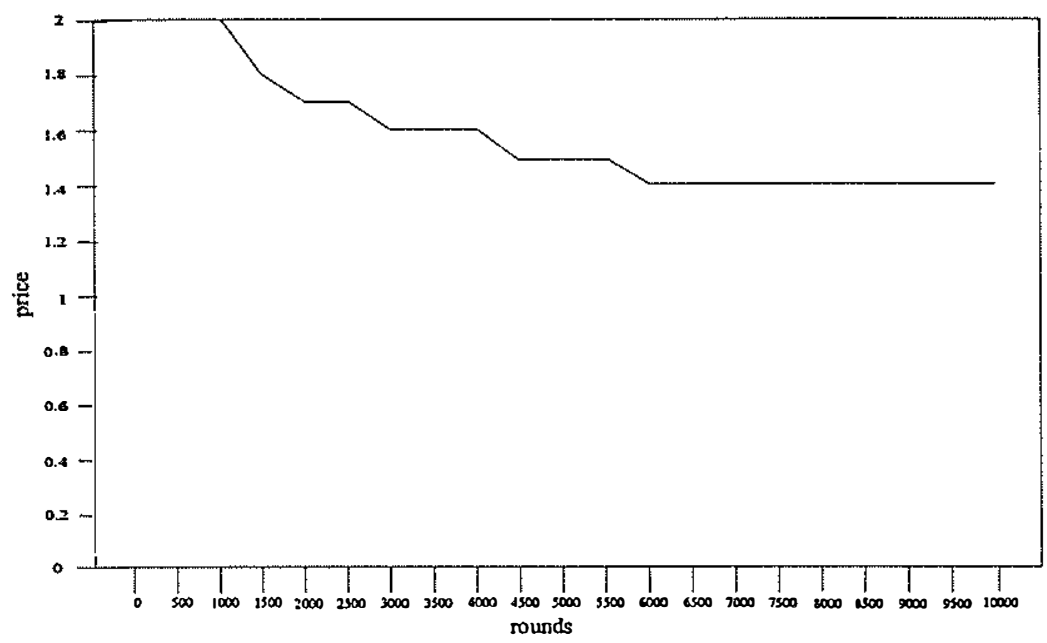

Figure 10-a.

The evolution of prices (players a and b behave competitively)

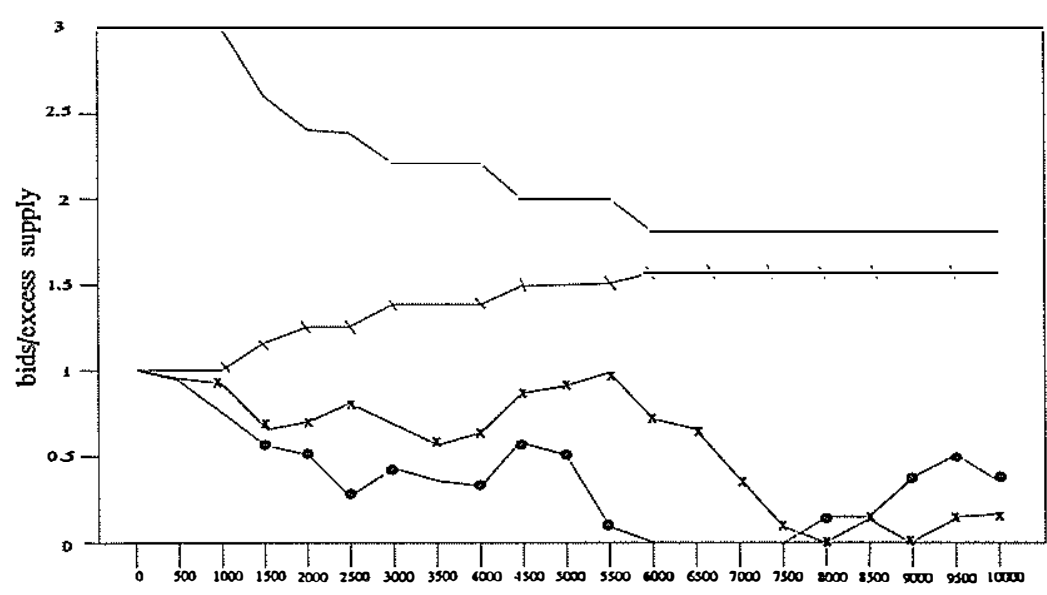

rounds

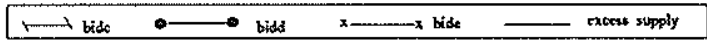

Figure 10-b.

The evolution of bids

(players a and b behave competitively) 


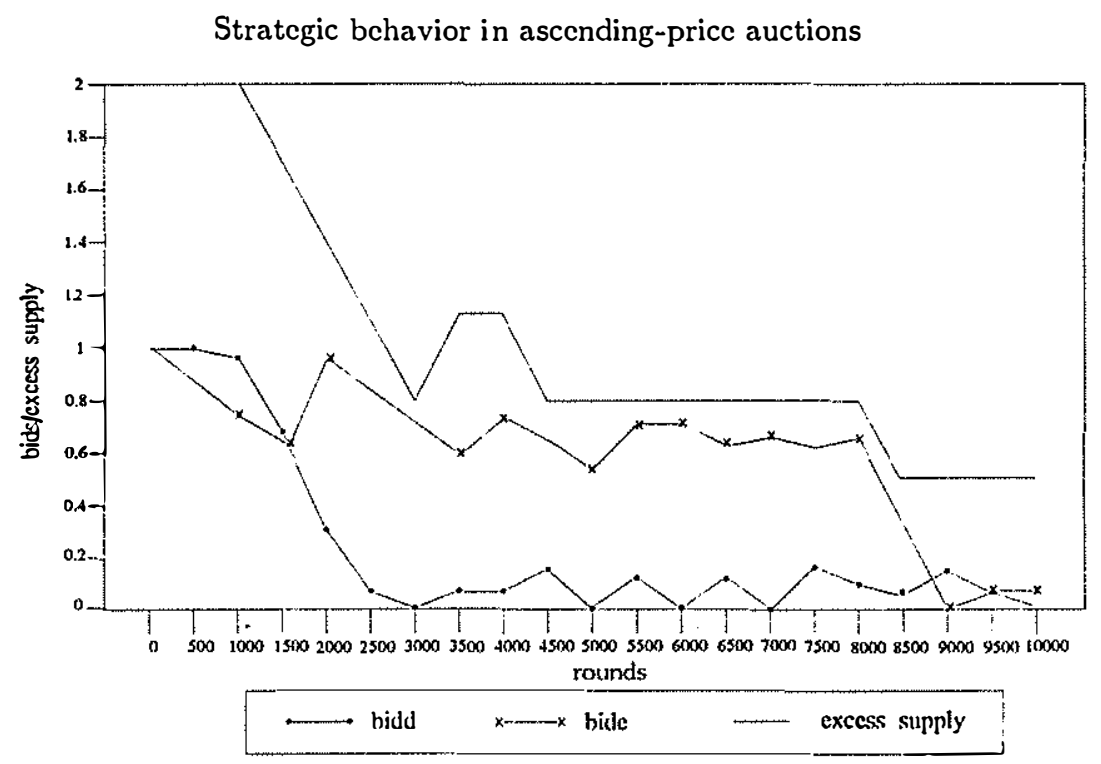

Figure 11.

The evolution of bids

(players a, b and c behave competitively) 